\title{
Outmigration survival of a threatened steelhead population through a tidal estuary
}

\author{
Rebecca A. Buchanan, Elissa Buttermore, and Joshua Israel
}

\begin{abstract}
Juvenile steelhead (Oncorhynchus mykiss) are exposed to numerous threats in heterogeneous, estuarine environments, yet understanding of survival patterns and processes during this migratory stage is often limited by studies that use surrogate species or are restricted in duration and spatial specificity. Lack of detailed survival information in this critical migratory stage limits the effectiveness of management to maintain juvenile life history diversity in threatened populations. We used acoustic telemetry with multistate mark-recapture models to investigate survival patterns during a key stage of the juvenile emigration of anadromous steelhead through the Sacramento-San Joaquin River Delta of California, United States, over multiple years, including three drought years. Survival was highly variable both within and among the six years of the study; estimated total survival through the Delta ranged from 0.06 (May 2014) to 0.69 (March 2011). Survival in the upstream reaches was associated with river discharge into the Delta, while survival through the lower reaches was associated with migration route. The lack of a single factor associated with survival in all reaches counteracts preconceived ideas of survival processes. Hydrodynamic manipulation and habitat improvements are recommended to support this anadromous population in a changing climate.
\end{abstract}

Résumé : Si les truites arc-en-ciel (Oncorhynchus mykiss) anadromes juvéniles sont exposées à de nombreuses menaces dans les milieux estuariens hétérogènes, la compréhension des motifs et processus de survie durant cette étape migratoire est souvent limitée par des études qui utilisent des espèces substitutives ou dont la durée et la spécificité spatiale sont restreintes. L'absence d'information détaillée sur la survie à cette étape migratoire critique limite l'efficacité de la gestion visant le maintien de la diversité des cycles biologiques de juvéniles au sein de populations menacées. Nous avons utilisé la télémétrie acoustique combinée à des modèles multi-états de lâcher-recapture pour examiner les motifs de survie durant une étape clé de l'émigration de truites arc-en-ciel anadromes juvéniles par le delta des fleuves Sacramento-San Joaquin en Californie (États-Unis) sur plusieurs années, incluant trois années de sécheresse. La survie était très variable durant chacune des six années de l'étude et d'une année à l'autre, le taux de survie total estimé dans le delta allant de 0,06 (mai 2014) à 0,69 (mars 2011). La survie dans les tronçons supérieurs était associée au débit des fleuves entrant dans le delta, alors que la survie dans les tronçons inférieurs était associée à l'itinéraire de migration. Le fait qu'il n'y a pas un facteur unique associé à la survie dans tous les tronçons contredit des idées préconçues concernant les processus de survie. La manipulation hydrodynamique et l'amélioration des habitats sont recommandées pour soutenir cette population anadrome dans un contexte de climat changeant. [Traduit par la Rédaction]

\section{Introduction}

Survival during juvenile emigration is considered a limiting factor for persistence of some populations of steelhead (anadromous rainbow trout, Oncorhynchus mykiss; Satterthwaite et al. 2010). Extensive study has been conducted on steelhead migration survival through managed rivers, but fewer studies have addressed survival in the estuarine environment in spatiotemporal detail despite observations that juvenile salmonid survival tends to be lower in estuaries than in neighboring environments (Welch et al. 2011; Thorstad et al. 2012). Estuary survival is challenging to study because of dynamic environments and complex migration routing, resulting in costly studies that often last only one or several years (e.g., Clemens et al. 2009; Harnish et al. 2012; Brodsky et al. 2020) or produce spatially inexplicit estimates (Rechisky et al. 2013; Sandstrom et al. 2020). The resulting lack of detailed spatiotemporal information on survival patterns and processes hinders management of imperiled steelhead populations, resulting in decisions based on untested conceptual models, survival estimates from surrogate species, or small data sets that underrepresent seasonal and annual variability or reflect overly large spatial scales.

The Central Valley (CV) Distinct Population Segment (DPS) of steelhead in California, United States, is an example of an imperiled population being managed in a highly degraded estuary with inadequate data. The CV DPS includes both naturally spawned fish from the Sacramento and San Joaquin river basins and fish reared in three hatchery programs in the CV. This DPS was listed as threatened under the US Endangered Species Act (1973) in 1998 (Lindley et al. 2006), and the Southern Sierra Nevada diversity group component of the DPS is of particular concern due to a recent multiyear drought. This southern population emigrates from the San Joaquin River (SJR) basin through the SacramentoSan Joaquin Delta (Delta), a heavily modified tidal estuary that provides water for municipal and agricultural use for millions of

Received 15 December 2020. Accepted 23 May 2021.

R.A. Buchanan. School of Aquatic and Fishery Sciences, University of Washington, 1325 Fourth Ave., Suite 1515, Seattle, WA 98195, USA.

E. Buttermore and J. Israel. US Bureau of Reclamation, 801 I Street, Suite 140, Sacramento, CA 95814, USA.

Corresponding author: Rebecca A. Buchanan (email: rabuchan@uw.edu).

() 2021 The Author(s). This work is licensed under a Creative Commons Attribution 4.0 International License (CC BY 4.0), which permits unrestricted use, distribution, and reproduction in any medium, provided the original author(s) and source are credited. 
Fig. 1. The study area in the southern Sacramento-San Joaquin River Delta (a) and major routes through the study area: San Joaquin River (SJR) route $(b)$ and Old River (OR) route $(c)$ from the head of OR and Turner Cut (TC) route (d) from the Turner Cut Junction (TCJ). Middle River (MR) is a subcomponent of all three routes. White arrows on route maps indicate predominant direction of fish movement in route through the interior Delta. Marked locations are Mokelumne River Fish Hatchery (MRFH; inset map), Durham Ferry (DF) release site, key cities, acoustic telemetry stations, river gauging stations, salvage facilities, and salvage release sites (i.e., after trucking from salvage facilities). Inset map shows state of California, United States (light shading) and the Delta, San Francisco Bay, and Pacific Ocean (dark shading); detailed area is marked with rectangle. Water export and salvage facilities are CVP = Central Valley Project and SWP $=$ State Water Project. Telemetry and gauging stations are defined in Table 2. Map data copyrighted OpenStreetMap contributors (Open Database License), downloaded via Overpass Turbo API (https://overpass-turbo.eu); Delta boundary data downloaded from https://gis.water.ca.gov/app/boundaries/. Map created using "rgdal” and "geosphere" packages in R (R Core Team 2020) and ArcMap 10.7.1 (Esri 2011).

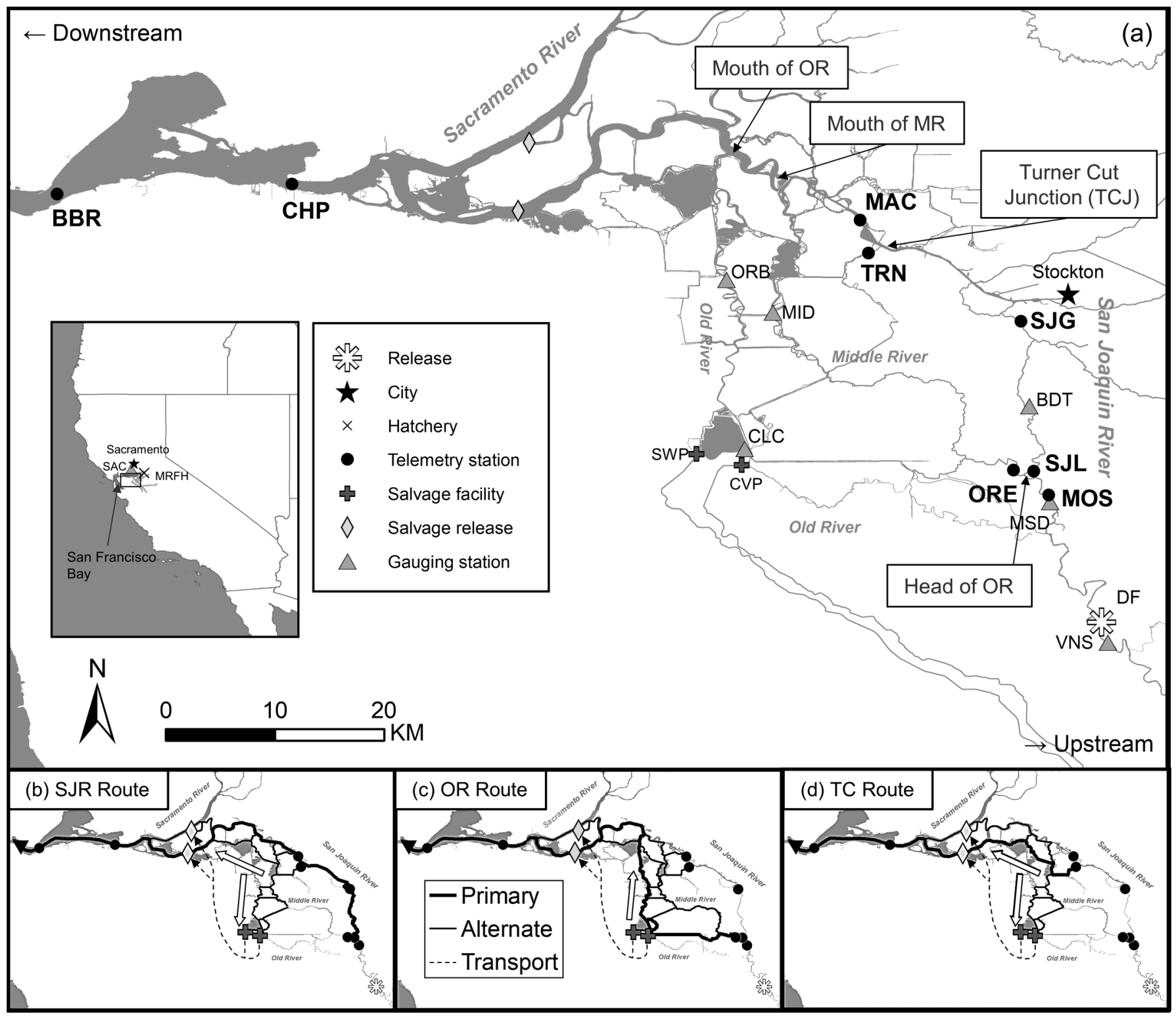

Californians (Fig. 1). Before now, there had been no direct information on Delta survival for this SJR steelhead population or how survival varies with environmental conditions and resource management operations. In the absence of such information, management decisions for this population have been based largely on juvenile Chinook salmon (Oncorhynchus tshawytscha) survival studies (McEwan 2001) and a series of untested hypotheses that Delta survival is higher for SJR steelhead when more water enters the Delta from upstream, when less water is extracted from the Delta for human use (export), and when fish remain in the mainstem migration route (National Marine Fisheries
Service 2009). It is unknown how relationships may change resulting from increased drought under climate change.

A six-year acoustic-telemetry study of juvenile steelhead began in spring 2011 designed to address uncertainties in SJR steelhead survival through the Delta and its relationship with the seasonal water management strategies used by federal and state agencies in the Delta. This paper presents the migration survival results for the six years of the study, discusses spatial patterns in survival estimates, investigates survival patterns compared to water management and environmental conditions, and explores drought effects on survival modeling. These results and the multistate 
Table 1. Release year, sample size $(N)$, release dates, mean (range) fork length at tagging, transmitter type (manufacturer and model), mean (range) tag burden (= tag weight/fish weight), and mean estimated tag life (SE; days) for release groups of juvenile steelhead.

\begin{tabular}{lllllll}
\hline Year & $N$ & Release dates & Fork length $(\mathrm{mm})$ & Tag type & Tag burden $(\%)$ & Tag life $($ days $)$ \\
\hline 2011 & 2196 & 22 March - 18 June & $277(149-396)$ & HTI 795 LD & $0.5(0.2-2.7)$ & $83.1(15.5)$ \\
2012 & 1435 & 4 April - 23 May & $234(115-316)$ & VEMCO V6 & $0.9(0.3-2.9)$ & $77.7(10.8)$ \\
2013 & 1425 & 6 March - 11 May & $212(115-300)$ & VEMCO V6 & $1.1(0.4-3.3)$ & $69.0(10.7)$ \\
$2014^{a}$ & 958 & 24 April - 24 May & $247(151-283)$ & VEMCO V5 & $0.5(0.3-1.2)$ & $75.2(15.8)$ \\
2015 & 1427 & 4 March - 25 April & $235(97-287)$ & VEMCO V5 & $0.5(0.3-3.8)$ & $65.4(7.6)$ \\
2016 & 1440 & 24 February - 30 April & $248(147-292)$ & VEMCO V5 & $0.5(0.3-2.2)$ & $63.9(6.4)$ \\
\hline
\end{tabular}

${ }^{a}$ A release group of 476 steelhead from March 2014 was omitted because of tag programming error.

analytical methods employed are expected to be informative for steelhead performance in other estuarine systems facing challenges from development and a globally changing climate.

\section{Materials and methods}

\section{Study area}

The Sacramento-San Joaquin Delta is the dendritic component of an inverted tidal estuary where the riverine environment transitions to a brackish estuarine environment, connecting the inland waters of the CV to a series of bays ending in the Pacific Ocean (Fig. 1). Delta aquatic habitats have been heavily modified through land use changes, altered flow patterns and nutrient input from upstream dams, and large-scale removal of Delta water for human population use (Yoshiyama et al. 1998; McEwan 2001; Sommer et al. 2007; Moyle et al. 2010). The Delta is also home to an increasing number of naturalized invasive plant and animal species, including large populations of non-native piscivorous fishes such as striped bass (Morone saxitilis) and largemouth bass (Micropterus salmoides) (Cohen and Carlton 1998; Nobriga and Feyrer 2007; Conrad et al. 2016). Little information is available on avian or mammalian predators of salmonids in the Delta, but such predation is likely to occur (Grossman 2016; Nelson et al. 2020). Decreased turbidity over recent decades has been associated with increased biomass of submerged aquatic vegetation and may contribute to predation risk (Gregory and Levings 1998; Hestir et al. 2016).

The Delta is dominated by the Sacramento River (SR) entering from the north and the SJR entering from the south. The region discussed in this paper is the southern portion of the Delta extending from the area near the source (head) of Old River (OR) in the south to Chipps Island in the west (SJR Delta; Fig. 1). The OR is the SJR's primary distributary in the Delta. Chipps Island is the downstream exit of the Delta and is the presumed migration target for juvenile salmonids emigrating seaward through this region. The SJR Delta is bounded to the south by Mossdale Bridge (hereinafter referred to as "Mossdale"; located adjacent to the MSD gauging station; Fig. 1) over the SJR south of OR, to the east and north by the lower SJR, and to the west by OR, which rejoins the SJR approximately 40 river kilometres (rkm) east of Chipps Island. Middle River (MR) is a distributary of OR that runs north between the SJR and OR and joins the SJR 4 rkm upstream of the SJR-OR convergence. Two large water pumping facilities are located off OR in the southwestern corner of the Delta, the federal Central Valley Project (CVP) and the State Water Project (SWP). Several channels connect the SJR to the interior region of the Delta downstream (i.e., north) of the OR source. The first such channel is Turner Cut (TC), which connects to the SJR at the Turner Cut Junction (TCJ; Fig. 1). The mouths of MR and OR are $11 \mathrm{rkm}$ and $15 \mathrm{rkm}$ downstream of TCJ, respectively (Fig. 1). The SJR is notably wider and more dominated by tidal forces downstream of TCJ.

There are multiple migration routes through the SJR Delta for juvenile salmonids emigrating past Mossdale (Fig. 1). Primary route selection occurs at the head of OR, where fish may either enter OR (OR route) or remain in the SJR (SJR route). Both the SJR route and the OR route include multiple subroutes in addition to travel entirely within the SJR and OR, respectively. Fish in the SJR route may either migrate entirely within the SJR to Chipps Island, or may enter the interior Delta through TC or other connections downstream (Fig. $1 b$ ). Fish in the OR route may migrate through Delta waters in either OR or MR to rejoin the SJR upstream (east) of Chipps Island (Fig. 1c). Alternatively, fish in both the OR and SJR routes may enter the water export facilities in the southwestern corner of the Delta, where they may be salvaged (i.e., captured) at the associated fish protection facilities or lost into the diversion pumps. Salvaged fish are transported by truck and released in the SJR or SR approximately $20 \mathrm{~km}$ upstream of Chipps Island (Fig. 1). The salvage route is more likely to be used by fish in the OR route because OR passes the entrances to both water export facilities, but fish in the SJR route may also be salvaged if they enter the interior Delta via TC or downstream (e.g., Fig. 1d).

A temporary rock barrier was installed in OR near its head in most study years to prevent salmonid access to that route under the expectation that survival is lower in the OR route. Although designed to block access, the barrier included culverts that allowed some passage of both water and fish. The barrier was not installed in 2011 because river discharge was too high, or in 2013. Each year in which the barrier was installed, some study fish reached the barrier either before construction was complete or after dismantling began.

\section{Field study methods}

The telemetry study's main objective was to estimate throughDelta survival from the head of OR to Chipps Island and to determine how that survival varied within and between study years. Study fish were obtained from the Mokelumne River Fish Hatchery (MRFH), one of the three artificial propagation programs included in the CV DPS. In the spring of each year from 2011 to 2016, 958 to 2196 one-year-old juvenile steelhead from MRFH were surgically implanted with microacoustic transmitters and released in the SJR at Durham Ferry (DF), located approximately $25 \mathrm{rkm}$ upstream of the head of OR and approximately $80 \mathrm{~km}$ from MRFH by truck (Fig. 1; Table 1). The 2011 study used the Hydroacoustic Technology, Inc. (HTI) Model 795 LD microacoustic tag (mean tag weight in air $=1.01 \mathrm{~g}$ ). The 2012 and 2013 studies used the VEMCO V6-180 kHz tag (1.05 g), and the 2014-2016 studies used the VEMCO V5-180 $\mathrm{kHz}$ tag $(0.67 \mathrm{~g})$. The tagging team included three to four surgeons each year; all surgeons received either new-surgeon training or refresher training annually. Fish fork length at the time of tagging ranged from 97 to $396 \mathrm{~mm}$ and averaged $212 \mathrm{~mm}$ (2013) to $277 \mathrm{~mm}$ (2011) each year (Table 1). Tag burden (i.e., the ratio of dry tag weight in air to fish weight) ranged from $0.2 \%$ to $3.8 \%$. In 2011 , tagging was performed at the California Department of Water Resources Collection, Handling, Transport, and Release Laboratory, located at the SWP's Skinner Fish Protection Facility approximately $50 \mathrm{~km}$ from DF by truck. In 2012-2016, tagging was performed at MRFH. After tagging, fish were trucked to the release site in insulated tanks designed 
Table 2. Geographic acronyms and site names including type and location indicated by river kilometre (rkm) measured from the Golden Gate Bridge (entrance to Pacific Ocean).

\begin{tabular}{lllr}
\hline Name & Type & Description $^{a}$ & rkm \\
\hline CV & Region & Central Valley of California & \\
MR & River & Middle River & \\
OR & River & Old River & \\
SJR & River & San Joaquin River & 137 \\
SR & River & Sacramento River & 213 \\
TC & Channel & Turner Cut & 195 \\
TCJ & River junction & Turner Cut Junction & 57 \\
MRFH & Fish hatchery & Mokelumne River Fish Hatchery & 77 \\
DF & Release site & Durham Ferry & 134 \\
BBR & Telemetry station & Benicia Bridge & 174 \\
CHP & Telemetry station & Chipps Island & 164 \\
MAC & Telemetry station & MacDonald Island & 150 \\
MOS & Telemetry station & Mossdale & 170 \\
ORE & Telemetry station & Old River near head & 138 \\
SJG & Telemetry station & San Joaquin at Garwood Bridge & 144 \\
SJL & Telemetry station & San Joaquin at Old River head & 146 \\
TRN & Telemetry station & Turner Cut & 161 \\
CVP & Water export facility & Central Valley Project & 142 \\
SWP & Water export facility & State Water Project & 126 \\
BDT & Gauging station & SJR at Brandt Bridge (Water Data Library B955740Q) & 175 \\
CLC & Gauging station & Clifton Court Forebay (CDEC CLC) & 123 \\
MID & Gauging station & MR at Bacon Island (USGS 11312676) \\
MSD & Gauging station & Mossdale Bridge (Water Data Library B95820Q) & 169 \\
ORB & Gauging station & OR at Bacon Island (USGS 11313405) & 198 \\
SAC & Gauging station & SR at Freeport (Dayflow SAC) \\
VNS & Gauging station & SJR at Vernalis (Dayflow SJR) &
\end{tabular}

Note: Distances to sites on the San Joaquin River are measured along the main stem of the river.

${ }^{a}$ Database source and site ID are identified for gauging stations.

for dissolved oxygen control and structural stability during transport. Fish were acclimatized prior to transfer into the SJR if the water temperature difference between the transport tanks and river was $>5^{\circ} \mathrm{C}$. Fish were held in the river at the release site at least $24 \mathrm{~h}$ before release. Fish tagging and handling procedures were based on those outlined in Adams et al. (1998) and Martinelli et al. (1998) and were updated to the Standard Operating Protocol developed by the US Geological Survey's (USGS) Columbia River Research Laboratory (Liedtke et al. 2012).

For each study year, in-tank tag-life studies were performed to measure the failure rate of tags used in the study. Between 82 and 149 tags were sampled across manufacturing lots and study months each year. Tag-life studies typically began at the time of the tagged fish release or within several weeks after release. Tank water temperature was maintained using river water pumped from OR to maintain temperatures similar to the Delta environment when tagged fish were migrating.

Tagged steelhead were monitored during their migration through the Delta using fixed-site acoustic hydrophones and receivers (telemetry stations; Fig. 1; Table 2). Each telemetry station was composed of 1 to 24 hydrophones to achieve complete coverage of the river channel. Hydrophone spacing across the river channel was based on range tests; at Chipps Island, HTI hydrophone spacing was approximately 150 to $300 \mathrm{~m}$, and VEMCO spacing was approximately 100 to $150 \mathrm{~m}$. Telemetry station locations were determined by the possible routes of juvenile salmon passage and the requirements of the statistical multistate mark-recapture model to distinguish and estimate movement, survival, and detection processes (described below). The locations of key stations remained constant across the six years of the study. Delta entry was denoted by detection at the Mossdale station (MOS) and Delta exit by detection on the Chipps Island station (CHP). The CHP station was composed of a dual (2011-2014) or triple $(2015,2016)$ line of hydrophones across the river for estimation of the detection efficiency at that site.
Telemetry stations were installed within $0.6-3.0 \mathrm{~km}$ downstream of the head of OR in both the SJR (SJL station) and OR (ORE station) for estimation of survival from the head of OR. In the SJR route, telemetry stations were also installed at Garwood Bridge (SJG) near the city of Stockton, California, at MacDonald Island (MAC), and in TC (TRN); together, detections on the MAC and TRN stations denoted arrival at TCJ. In 2014-2016, a telemetry station was installed at Benicia Bridge (BBR) downstream of Chipps Island and used to estimate the detection efficiency at CHP.

\section{Covariates}

Environmental and operational data from various gauging and monitoring stations throughout the Delta were downloaded from several online databases: California Department of Water Resources' Dayflow database (https://data.cnra.ca.gov/dataset/dayflow: river discharge, Delta inflow and outflow, export rate, salinity), the California Data Exchange Center (CDEC; https://cdec.water.ca.gov: temperature), the California Water Data Library (water.ca.gov/ waterdatalibrary: temperature, river discharge), and the USGS National Water Information System (waterdata.usgs.gov/nwis: river discharge). River discharge and temperature data were reviewed for quality and obvious errors were omitted. In particular, records were removed if they were marked as missing by the database, were out of sequence with neighboring readings, or were part of a string of three or more identical readings (discharge only).

Covariates were selected to represent environmental and operational conditions in several ways to address management questions (Table 3). Environmental conditions were represented by measures of river flow (discharge), temperature, salinity, and time of day. The primary measure of river flow was the SJR discharge into the Delta (SJR inflow) measured near Vernalis, California (VNS). The Delta inflow from the SR (SR inflow), measured at Freeport, California (SAC), was also considered because flow conditions in 
Table 3. Covariates evaluated in individual-based models.

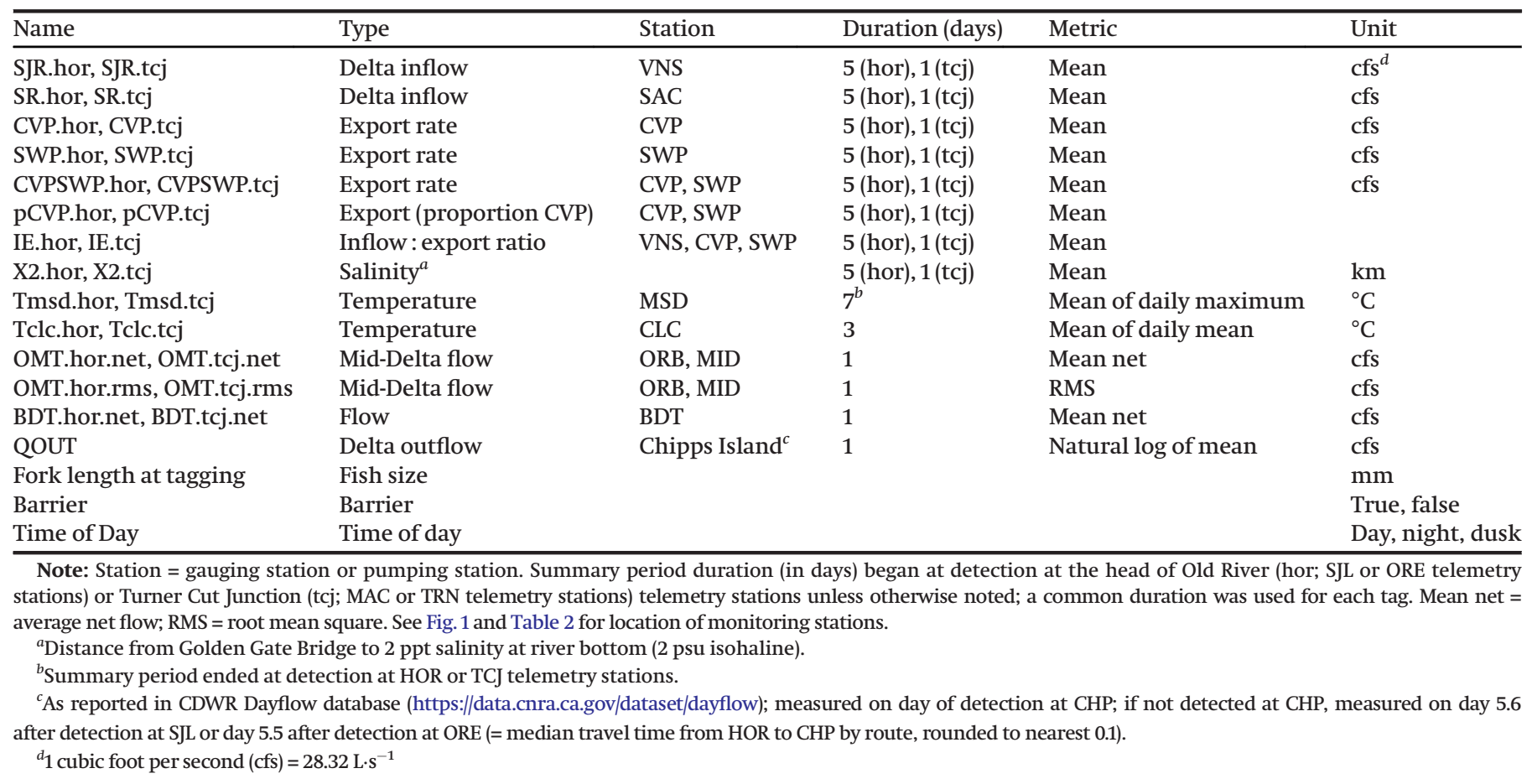

northern and western part of the study area are influenced by SR inflow (Monsen et al. 2007; Cavallo et al. 2013). River flow measurements were used from locations within the Delta, including the SJR at Brandt Bridge (between the head of OR and Stockton, California; BDT), OR at Bacon Island (ORB), and MR at Bacon Island (MID) (Fig. 1; Table 2). The ORB and MID 15-minute river flow measures were summed to provide an overall measure of flow conditions in the interior Delta north of the water export facilities: OMT = ORB + MID. Water temperature was measured at Mossdale (MSD) and Clifton Court Forebay (CLC). Salinity was represented by the measure $\mathrm{X} 2$ (Dayflow), which reports the distance $(\mathrm{km})$ upstream from the Golden Gate Bridge where the river bottom salinity concentration reaches $2 \mathrm{ppt}(2 \mathrm{psu}$ isohaline). Time of day was measured by whether fish were detected at the upstream boundary of the survival reach during day, night, or crepuscular periods.

Operational conditions reflected management of the water project operations, including reservoir releases upstream, barrier installation, and water export rates. Reservoir releases were represented by the Delta inflow measures, which were thus both environmental and operational variables. The status of the barrier at the head of OR was defined as "present" if the tagged fish was last detected at the SJL or ORE telemetry stations between the date of barrier closure during installation and the date of barrier opening during removal, or as "absent" otherwise. Water export rates were represented by the daily export rates reported for the CVP and SWP. The combined export rate (CVP + SWP) and the CVP proportion of the combined export rate $(\mathrm{pCVP}=\mathrm{CVP} /$ $(\mathrm{CVP}+\mathrm{SWP}))$ were also considered. Finally, a regulatory metric defined as the ratio of SJR inflow to the combined export rate, or the "I:E ratio", was considered.

Environmental and operational variables were recorded either daily (Delta inflow, export rates, I:E ratio, X2) or at 15-minute intervals (river flow, temperature). To reduce effects of subhourly fluctuations in measurements and to better represent conditions when the fish were actually migrating through the system, the measured conditions were summarized over a time period defined by tag detection at either the OR head or TCJ. The median travel time from the head of OR to Chipps Island (approximately 5.6 days) was used to select a 5-day summary period for measures of Delta inflow, exports, the I:E ratio, and X2 starting at the time of detection at the head of OR. Delta inflow, exports, I:E ratio, and $\mathrm{X} 2$ were also summarized over a 1-day period starting at tag detection at TCJ, for modeling survival in the lower reaches of the Delta. SJR inflow and the I:E ratio were summarized as the natural $\log$ of the mean daily reading; SR inflow, X2, and export measures were summarized as the mean of the daily readings. The gauging station readings of river flow at the BDT, ORB, and MID stations were missing a considerable amount of data in some years, and the longer summarization periods had more missing data than shorter periods; thus, the BDT and OMT measures used 1-day summarization periods to maximize the amount of data available. River flow at BDT and OMT were summarized as the average (i.e., arithmetic mean) of the 15-minute event data during the summarization period; this measure accounted for changes in direction of river flow due to tidal cycles or water pumping operations and represented the average net river flow during the summary period. Reverse flows were particularly common in the mid-Delta; thus, an alternative measure of OMT river flow used the root mean square of the 15-minute event data and represented the average magnitude of flow passing the gauging station during the summary period. Water temperature at MSD was represented as the 7-day average daily maximum temperature (7DADM, the usual management metric from this site) through the time period that ended at detection at the head of OR or TCJ. Water temperature at the CLC station was summarized as the average over a 3-day period starting at the time of tag detection at the head of OR.

A daily index of Delta outflow was used to represent flow conditions at the time of tag passage of the CHP telemetry station: QOUT, using the outflow index from the Dayflow database. The metric QOUT was measured on the day of tag detection at CHP, or on the day of expected tag detection for tags not observed at CHP. The day of expected tag detection was estimated using the median observed travel time from the head of OR to CHP using data pooled across all years and categorized by migration route: 
5.6 days after tag detection at SJL, and 5.5 days after tag detection at ORE.

\section{Statistical methods}

\section{Data processing}

The raw acoustic tag detection data were processed into detection events for each tag by the USGS lab in Cook, Washington (2011) or Sacramento, California (2012-2016). The processed detection data were transferred to the University of Washington, Seattle, Washington, United States, for further processing into chronological detection histories. The study fish were expected to be migrating in a seaward direction; however, the tidal nature of the Delta meant that study fish may have temporarily moved upstream on reverse flows. The detection histories used the final pass of the study fish past each receiver or river junction as the best representation of the fish fate.

The possibility of a predatory fish eating a tagged steelhead and then moving past a receiver with the active acoustic tag still in its gut raised the potential for biased survival estimates. Suspected detections of predatory fish on steelhead tags were identified and removed from the data set using a "predator filter". The predator filter was based on assumed behavioral differences between juvenile steelhead and resident predatory fish such as juvenile and subadult bass. It focused on residence time in the vicinity of the receivers or in regions of the Delta, movements directed against river flow, and travel time between receivers. The predator filter removed between $7.3 \%$ and $13.9 \%$ of the detection events each year, including a total of 111 (5.4\%) of the detection events at Chipps Island (3.5\% of the tags detected there). More information on the predator filter is available in Buchanan (2018a, 2018b, 2018c) and US Bureau of Reclamation (USBR 2018a, 2018b, 2018c).

\section{Survival estimation}

Survival was estimated from the filtered detection data using a multistate mark-recapture (MSMR) model in which migration route was represented by model state (Fig. 2; Perry et al. 2010; Buchanan et al. 2013, 2018). Model parameters consisted of reach-specific survival probabilities $(S)$, junction-specific route selection probabilities $(\Psi)$, and site-specific conditional detection probabilities (i.e., detection efficiencies, $P$ ). In some reaches, survival and route selection could not be separately estimated, and the joint probability of route selection and survival was estimated instead. A multinomial likelihood function was constructed under the assumptions of common survival, route selection, transition, and detection probabilities within a release group and independent detection events. The MSMR model accounted for imperfect detection efficiencies in estimating survival and incorporated multiple migration routes to estimate routespecific or region-specific survival probabilities. Survival was estimated for various regions in the Delta, including (1) throughDelta survival (i.e., Mossdale to Chipps Island: MOS to CHP), (2) route-specific survival from the head of OR to Chipps Island (SJL-ORE to CHP), (3) survival from the head of OR to TCJ (SJL to MAC-TRN), and (4) route-specific survival from TCJ to Chipps Island (MAC-TRN to CHP). Special attention was given to the SJR route because it is typically considered preferable to the OR route. Cumulative survival along the SJR route was estimated to identify regions where the mortality rate was highest.

The precise structure of the MSMR model each year depended on the locations of the detection sites. Although additional detection sites were added in later years as study objectives expanded, the same core sites were used in all years. Figure 2 shows the model structure on the scale addressed in this paper, common to all years. The full model schematic for each individual year can be found in the annual reports (Buchanan 2018a, 2018b, 2018c; USBR 2018a, 2018b, 2018c).
Fig. 2. Schematic of multistate mark-recapture model to estimate survival of juvenile steelhead from Mossdale (MOS) through the Delta to Chipps Island (CHP). The Head of Old River (OR) is monitored by telemetry stations at SJL (San Joaquin River [SJR] route) and ORE (OR route). The Turner Cut Junction is monitored by telemetry stations at MacDonald Island (MAC) and Turner Cut (TRN). SJG is the SJR at Garwood Bridge. Site BBR (Benicia Bridge) was available only in 2014, 2015, and 2016. Horizontal lines indicated acoustic receiver lines; parallel lines indicate dual-line or triple-line receiver array. The third receiver line at CHP was available only in 2015. Model parameters are probabilities of reach survival $(S)$, detection $(P)$, route selection $(\Psi)$, and the last reach parameter $\lambda=\mathrm{SP}$.

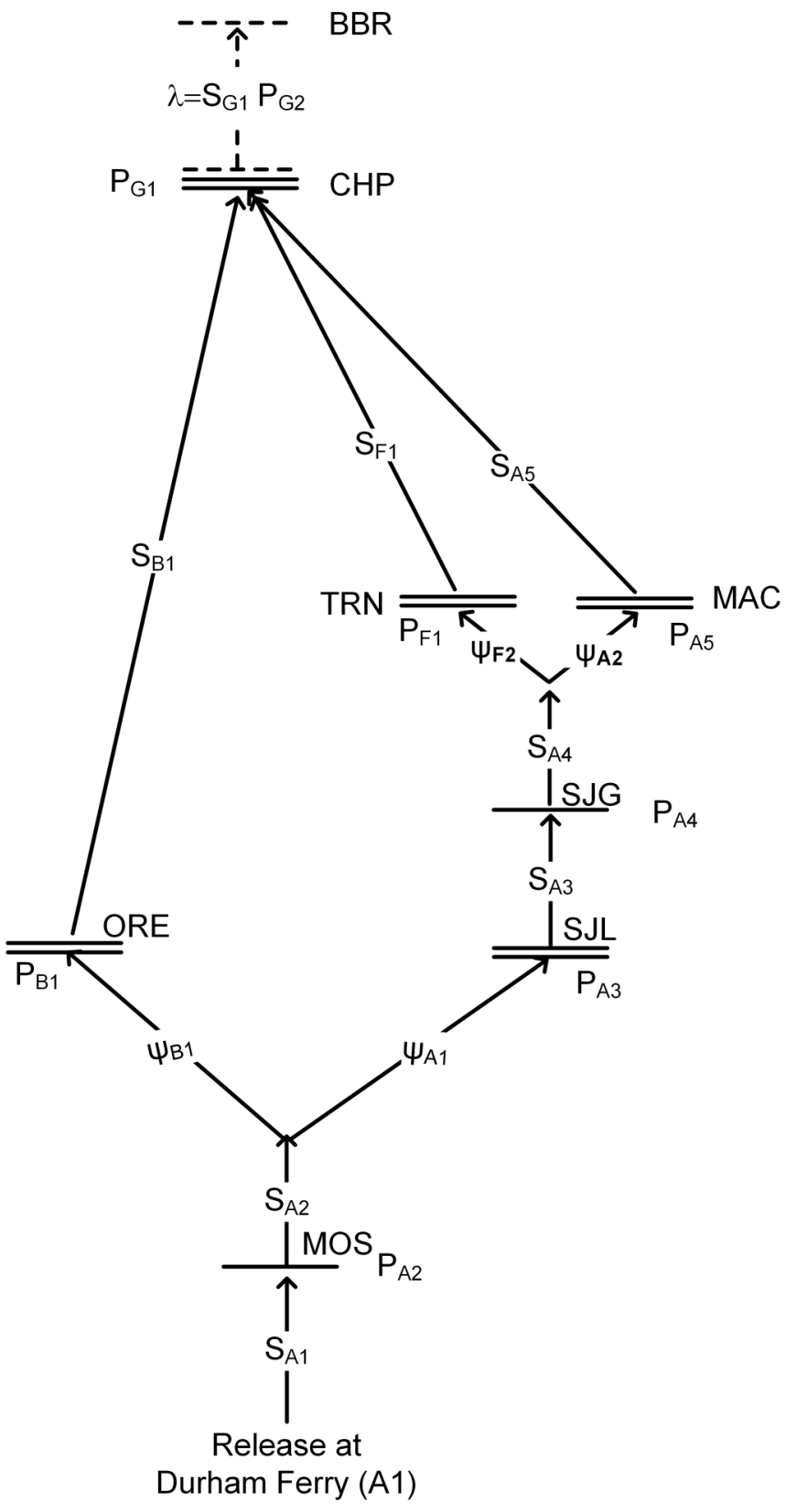

For each study year, the MSMR model was fit separately to each release group and annual averages were computed of the releasespecific parameter estimates weighted by release size. The MSMR model was fit to data using maximum likelihood estimation in the software program USER (Lady and Skalski 2009). On occasion, the full model had to be simplified to account for sparse data 
through certain routes, resulting in loss of some route-specific information but not affecting the estimate of overall through-Delta survival; for example, there were too few detections at TCJ from the March release in 2013 to estimate survival from this junction to Chipps Island, but overall survival from Mossdale to Chipps Island in the SJR route could be inferred.

Tag life was measured as the time between tag activation and final tag failure time in the in-tank tag-life studies. Observed tag survival was modeled separately for each year using the fourparameter vitality curve (Li and Anderson 2009). The estimated fish survival probabilities in the MSMR model were adjusted for tag failure using methods adapted from Townsend et al. (2006) using the observed travel time per release group from tag activation to downstream detection sites and the fitted vitality curves (Buchanan et al. 2018). Travel time and the associated probability of tag survival to Chipps Island were estimated separately by migration route for this purpose.

\section{Survival modeling}

The relationship between steelhead survival through the Delta and covariates was investigated for three spatial regions: from the head of OR to Chipps Island, from the head of OR to TCJ, and from TCJ to Chipps Island. Statistical survival models were developed using individual-based generalized linear models (GLM) with a multinomial error structure and fixed effects (McCullagh and Nelder 1989; Buchanan and Skalski 2020).

The form of the GLM depended on the spatial region being considered. Survival to Chipps Island was modeled using tags detected at the telemetry stations at the upstream end of the reach (virtual release): SJL and ORE for the head of OR, and MAC and TRN for TCJ (Fig. 2). Tag detections at the CHP and BBR telemetry stations were modeled as a multinomial random variable in a mark-recapture framework in which both the survival component and the detection component were modeled as functions of covariates. The detection model was defined first and modeled detection probabilities at CHP and BBR as a function of the measure of Delta outflow, QOUT, on the log scale using a GLM with a logit link; detailed methods on the detection probability modeling are provided in the online Supplemental Material ${ }^{1}$. The survival model also used a logit link to express the probability of survival to Chipps Island as a function of covariates, including an offset for the probability of tag survival.

For survival from the head of OR to TCJ, the lack of river gauging stations near TCJ complicated modeling of route selection and detection probabilities at the TCJ telemetry stations (MAC and TRN) and made a multinomial GLM impractical. Thus, a GLM with binomial errors and logit link function was used to relate detection at the TCJ telemetry stations to covariates for tags that were previously detected at SJL. Inference to survival required the assumption that all tags present at MAC and TRN were detected there (i.e., $P_{\text {MAC }}=P_{\text {TRN }}=1$ ). The potential bias in survival inference due to imperfect detection efficiencies at MAC and TRN was assessed through a simulation process. For each simulation, a random subset of the tags that were not detected at MAC or TRN was reassigned to "detected" status; the number of tags selected for reassignment equaled the estimated number of tags that missed detection at MAC or TRN based on the markrecapture estimates of survival and detection probabilities. The final GLMs identified in the modeling process were refit to the new data set that consisted of the observed and simulated tag detections. The mean regression parameter estimates were computed over 100 simulations and compared to the parameter estimates from the observed data set.

Both group-level and individual-level variables were used to account for variation in survival on all three spatial scales. The default baseline model used for assessment of environmental and operational covariates included fixed effects of year, migration route, and barrier, as well as time of day of detection at the upstream end of the reach and fork length at tagging. An interaction effect between route and barrier was included because the barrier both blocks most fish access to the OR route and influences the river flow entering the route. The default baseline model had the following form:

$$
\operatorname{logit}\left(S_{y r b i}\right)=\beta_{0 y}+\rho I_{r}+\tau I_{b}+\gamma I_{r} I_{b}+\delta_{d} I_{d}+\beta_{L} L_{i}
$$

where logit(.) is the logit link function, $\beta_{0 y}$ is the baseline intercept for year $y$ (SJR route, no barrier, departure during day), $\rho, \tau$, and $\delta_{d}$ are intercept adjustments and $I_{r}, I_{b}$, and $I_{d}$ are indicator functions for the non-SJR route (i.e., OR route for survival from the head of OR, or TC route from TCJ), barrier, and time of day (night or crepuscular period), respectively, $\gamma$, is the additional intercept adjustment for the combination of barrier and OR route, $\beta_{L}$ is the slope (regression coefficient) for fork length, and $L_{i}$ is fork length for fish $i$. Terms in the default baseline model were retained if they were significant at the $5 \%$ level from $F$ tests. The default baseline model omitted the $\rho$ and $\gamma$ terms for survival from the Head of OR to TCJ, and omitted the $\gamma$ term for survival from TCJ to Chipps Island.

Environmental and operational variables $(X)$ were added to the baseline model using forward stepwise model selection (F tests); both main effects and interaction effects with the baseline variables were considered. Baseline variable effects were retested with variable $X$ in the model, and Bonferroni corrections were used to account for multiple testing (Sokal and Rohlf 1995). The Akaike information criterion (AIC; Burnham and Anderson 2002) was used to select among single-variable models for different environmental and operational variables. The single-variable model with the lowest AIC was used as the basis of the next step in model construction, with the possibility of adding other $X$ variables. Selected models were significant if the experimentwise (i.e., multiple comparison) type I error rate was $<0.05$ and $\Delta$ AIC $<2$ compared to the model with the smallest AIC value.

Goodness-of-fit was investigated in two ways. First, the area under the curve (AUC) was computed for the Receiver Operating Curve (Nam and D'Agostino 2002); values $>0.7$ were considered acceptable (Hosmer and Lemeshow 2000). Second, the predicted joint probability of fish and tag survival and detection at the downstream site (either CHP or TCJ) was visually compared to the observed proportion of tags detected there, computed for groups of individual tags ordered by model predictions. Fifteen approximately equal-sized groups were used for both assessments.

\section{Drought effects}

The potential effect of drought on steelhead survival patterns through the Delta was investigated in several ways. Drought years were considered to be those classified as "critical" for water resource planning by the California Department of Water Resources: critical years were 2013, 2014, and 2015, while 2011 was classified as "wet" and 2012 and 2016 were both classified as "dry" (cdec.water.ca.gov/ cgi-progs/iodir/WSIHIST). Drought was hypothesized to affect survival in a number of possible ways: lower overall survival from the head of OR or TCJ to Chipps Island in either route, lower survival to TCJ, a shift upstream of the reach with the highest mortality rate per kilometre, or lower variability in survival estimates. Differences in the magnitude of survival estimates by drought status were tested using a one-way weighted ANOVA of the log-transformed survival estimates with weights equal to the inverse squared coefficient of variation. Visual inspection of cumulative survival through the SJR route was used to identify the reach of highest mortality rate per kilometre for

${ }^{1}$ Supplementary data are available with the article at https://doi.org/10.1139/cjfas-2020-0467. 
Fig. 3. Mean daily San Joaquin River discharge (flow) at the VNS gauging station near Vernalis, California, (SJR inflow) through the study period for each year. Points indicate the observed mean daily discharge on the first day of each release group. (Note: $1 \mathrm{cfs}=28.32 \mathrm{~L} \cdot \mathrm{s}^{-1}$.) [Colour online.]

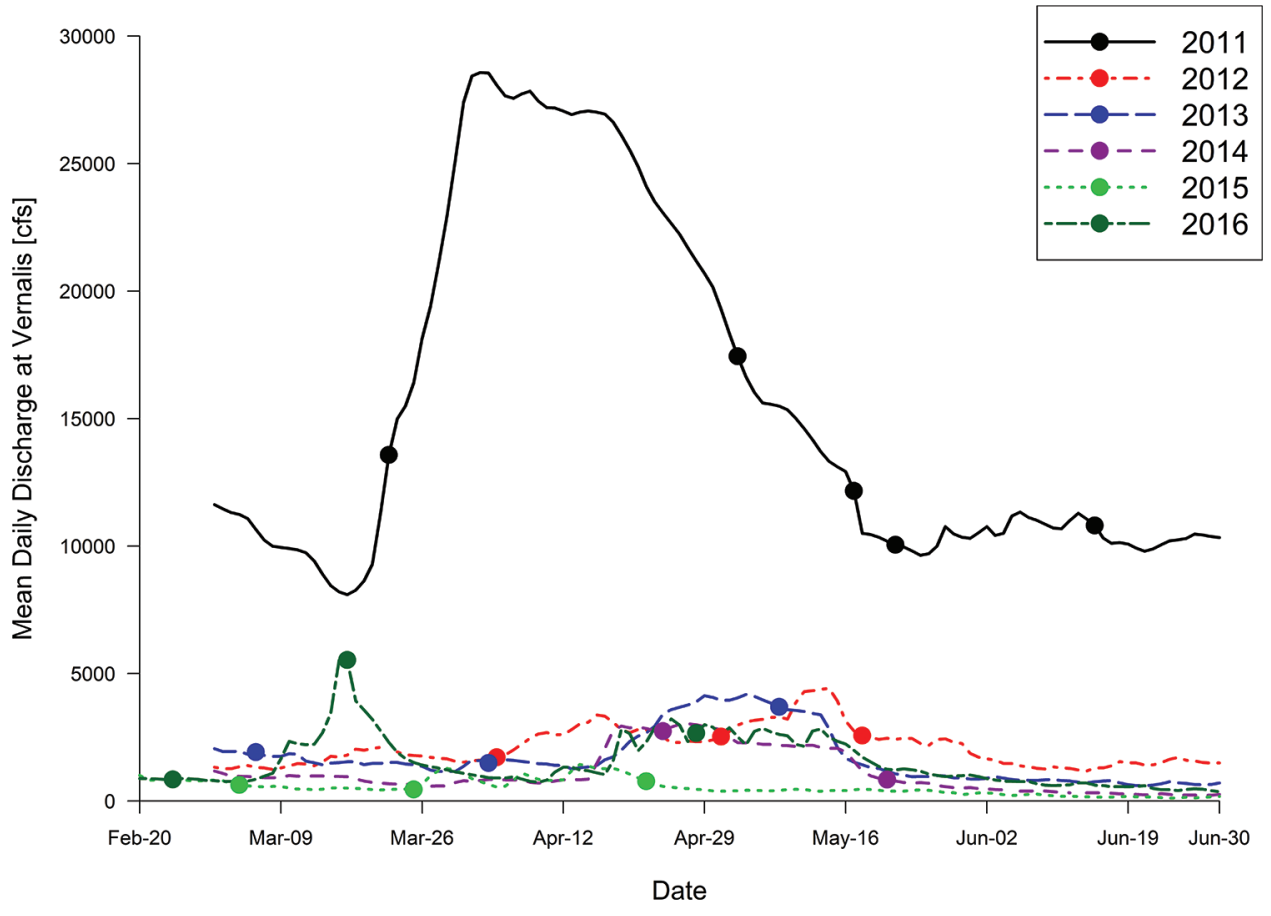

each year. Another possible ramification of drought status is alteration of the survival dynamics across the system, in which different relationships between covariates and survival are observed under different degrees of drought conditions. For example, the annual variability in survival represented by yearspecific intercepts in GLM models may be primarily associated with drought status. This possibility was investigated by comparing the model fits of a year-based model as defined above and a droughtbased model using fixed drought effects in place of fixed year effects ( $F$ tests); the final model structure for each spatial region was used as the basis for testing. The comparison was performed using the two-way classification of drought vs. non-drought years (2013-2015 vs. 2011, 2012, and 2016), and also using a three-way classification of wet (2011), dry (2012, 2016), and drought (2013-2015) years.

\section{Results}

\section{Delta conditions}

The study year 2011 had considerably higher river discharge than any of the later years in the study, following a wet autumn in 2010 and high precipitation events in February and March 2011 (Fig. 3). Mean daily SJR inflow into the Delta measured at VNS averaged 15491 cubic feet per second $\left(\mathrm{cfs} ; 1 \mathrm{cfs}=28.32 \mathrm{~L} \cdot \mathrm{s}^{-1}\right)$ during March-June 2011, and 739 to 2721 cfs during the study months in 2012-2016. The pattern of covariate values used in the survival modeling showed no overlap in SJR inflow values between 2011 and the other study years, and noticeably lower inflow in 2015 (Fig. 4a). Average combined export rates (CVP+SWP) were $<5000 \mathrm{cfs}$ throughout most of the study periods but increased to $>10000 \mathrm{cfs}$ at the end of the 2011 study. The I:E ratio tended to be higher for 2011 and lowest for 2015 and 2016. As with SJR inflow and exports, the 1-day average net mid-Delta flow (OMT) was most variable for 2011 and was mostly $<0$ cfs for 2012-2016 (Fig. 4). Temperature at MSD was inversely related to river flow $(r=-0.69)$. The salinity measure $\mathrm{X} 2$ was highest in the extreme drought years of 2014 and 2015 and lowest in 2011 and 2016 (Fig. 4f).
Survival: Mossdale to Chipps Island

Estimates of through-Delta survival from Mossdale to Chipps Island ranged from $0.06(\widehat{\mathrm{SE}}=0.02)$ for the May 2014 release to $0.69(\widehat{\mathrm{SE}}=0.03)$ for the March 2011 release; annual estimates were lowest in $2013(0.14, \widehat{\mathrm{SE}}=0.01)$ and highest in $2011(0.54, \widehat{\mathrm{SE}}=0.01$; Table 4). In addition to the annual differences, there was variation among release groups within each year. For example, the April 2014 release had considerably higher survival $(0.43, \widehat{\mathrm{SE}}=$ $0.03)$ than the May release of the same year $(0.06, \widehat{S E}=0.02)$ (Table 4). Travel time from Mossdale through the Delta to Chipps Island varied from 1.5 to 35.0 days; the median travel time each year ranged from 5.8 to 8.0 days. Conditional detection probability estimates were high at the CHP telemetry station throughout most of the study: 15 of the 19 estimates were $\geq 0.95$ (Table 4).

\section{Survival: head of Old River to Chipps Island}

Travel time from the head of OR to Chipps Island ranged from 1.4 to 34.9 days; the median travel time through this region was 5.6 days, and neither the SJR route nor the OR route had a consistently shorter travel time (Fig. 5). Survival estimates from the head of OR to Chipps Island ranged from 0 (March 2013) to 0.72 $(\widehat{\mathrm{SE}}=0.04$; March 2011) for the SJR route, and from 0.05 ( $\widehat{\mathrm{SE}}=0.03$; mid-May 2012) to $0.71(\widehat{S E}=0.04$; March 2011) for the OR route (Table 4). The estimated route selection probability for the SJR route ranged from $0.08(\widehat{\mathrm{SE}}=0.02$; March 2013) to $0.97(\widehat{\mathrm{SE}}=0.01$, early May 2012) (Table S1, Supplemental Material ${ }^{1}$ ). Within the SJR route between the head of OR and Chipps Island, cumulative survival declined most sharply in the region upstream of SJG for the drought years of 2013-2015, whereas the other years showed either little difference in the per-kilometre survival rate throughout the route (e.g., 2011, 2016) or else had a higher mortality rate downstream of TCJ (2012) (Fig. 6).

Survival and detection modeling on this spatial scale was based on 2515 tags detected at SJL and 2122 tags detected at ORE; 1772 of these tags were subsequently detected at either CHP or BBR. $F$ tests indicated an association between Delta outflow and detection probability at Delta exit $(P=0.0107)$. AIC selected unique 
Fig. 4. Box plots of key covariates by study year. Box represents interquartile range and thick horizontal line is median. Covariates are (a) 5-day average SJR inflow (log scale; $\left.c f s ; 1 \mathrm{cfs}=28.32 \mathrm{~L} \cdot \mathrm{s}^{-1}\right)$, (b) 5-day average combined export rate (cfs), (c) 5-day average I:E ratio (log scale), (d) 1-day average net Old River - Middle River (OMT) flow (cfs), (e) 7DADM temperature at MSD $\left({ }^{\circ} \mathrm{C}\right)$, and $(f)$ 5-day average X2 value $(\mathrm{km})$.
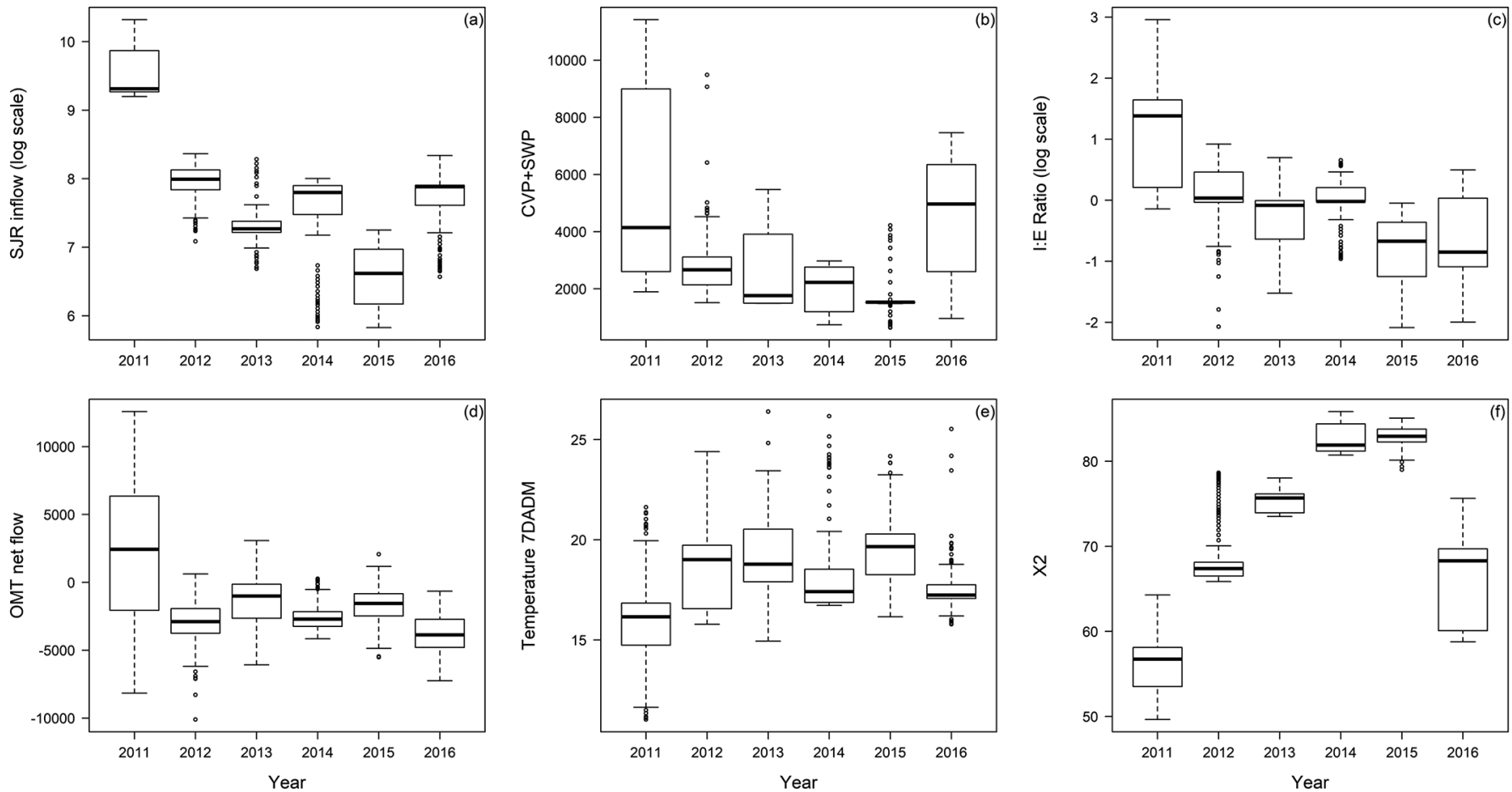

Table 4. Release dates, number $(N)$ released at Durham Ferry, and estimates (standard errors in parentheses) of the probabilities of survival ( $S$ ) and detection $(P)$ for release groups of acoustic-tagged juvenile steelhead.

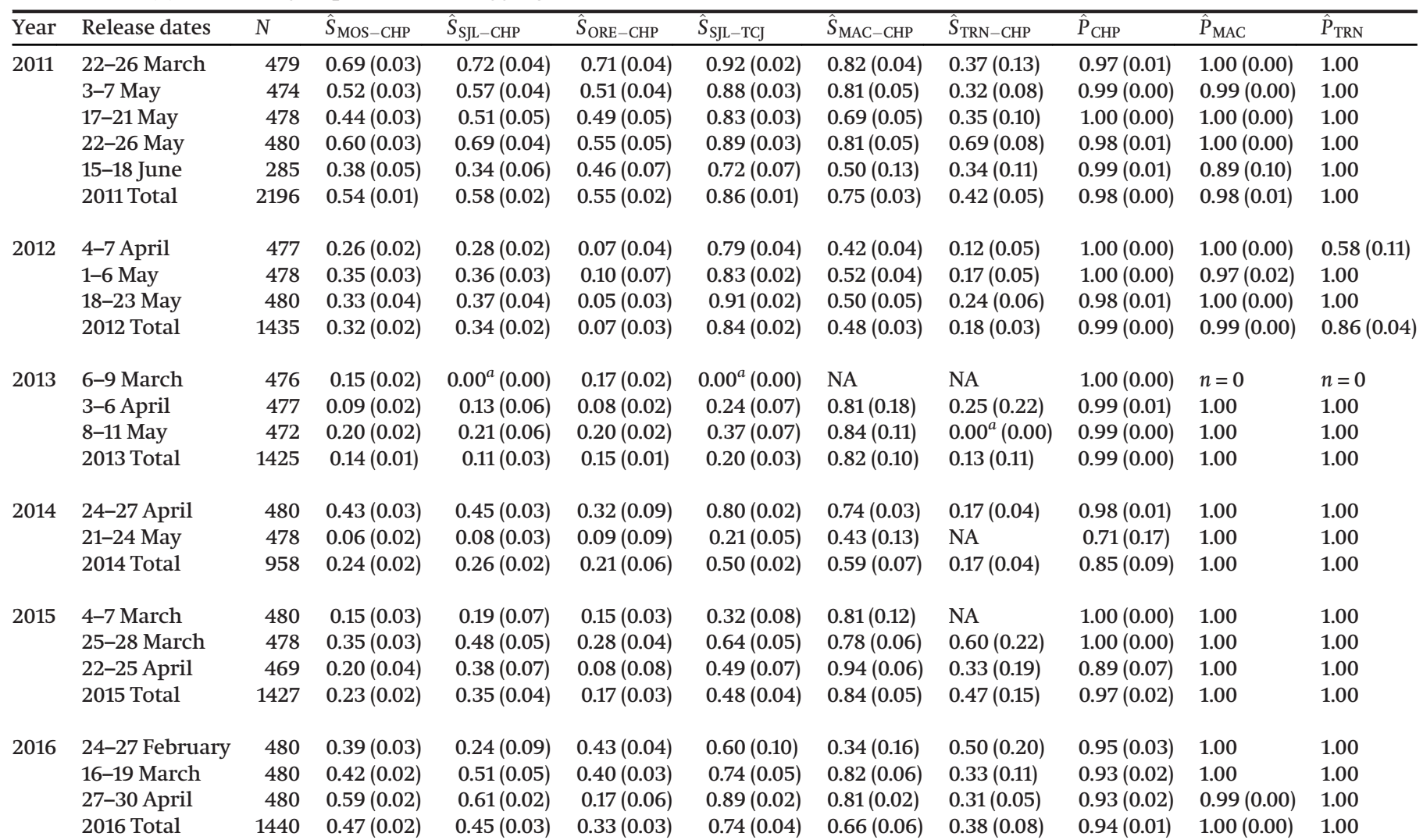

Note: TCJ = Turner Cut Junction, denoted by the MAC and TRN telemetry stations. See Fig. 1 for station locations. Values without standard errors were estimated at exactly $1.00 ; n=0$ indicates 0 detections.

${ }^{a}$ Under assumption of $100 \%$ conditional detection probability. 
Fig. 5. Cumulative travel time (days) from the Head of Old River to Chipps Island, by year and route. SJR = San Joaquin River, OR = Old River. Icon marks latest observed travel time for the study year. [Colour online.]

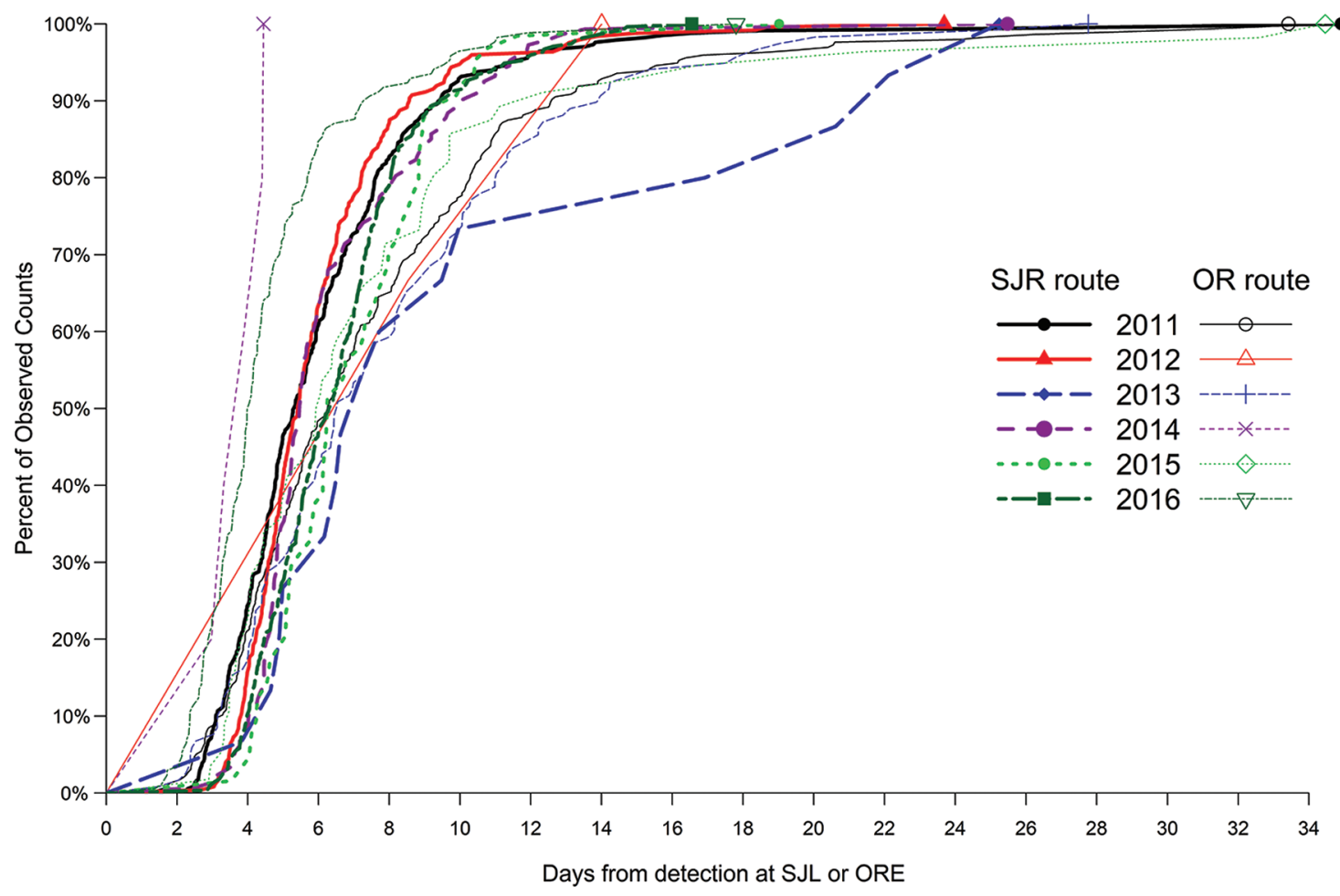

detection models using Delta outflow for the CHP receiver lines and $\lambda$ to the BBR station ( $\triangle \mathrm{AIC} \geq 38.7$ ).

The baseline survival model to Chipps Island retained the effects of year, barrier, and fork length at tagging $(P<0.0001$ for year and $P \leq 0.0207$ for barrier and fork length). Migration route and the time of day at the head of OR were not associated with survival on this spatial scale $(P \geq 0.1282)$ and were omitted from the model. The SJR measure of Delta inflow, temperature, the I:E ratio, and X2 were all associated with survival when effects of year, barrier, and fork length were accounted for $(P \leq 0.0016$; testwise $\alpha=0.0042$; Table 5). The mean mid-Delta flow, SR inflow, and CVP proportion of exports were also associated with survival at the testwise 0.05 level $(P \leq 0.0196)$. The top covariate selected by AIC was SJR inflow (SJR.hor, $P<0.0001, \Delta$ AIC $\geq 31.87$; Table 5). When SJR inflow was included in the model, no other covariates had statistically significant added effects $(P \geq 0.0653$ vs. testwise $\alpha=0.0091$ ). The SJR inflow model achieved acceptable fit based on the AUC of the Receiver Operating Characteristic curve (AUC = 0.72). However, all models had AUC $\geq 0.70$ (i.e., considered acceptable) including the baseline model (Table 5), demonstrating little added explanatory value of any of the covariates once year, barrier status, and fork length were included. For comparison, a model that included SJR inflow but omitted year, barrier, and fork length had AUC $=0.66$, indicating the relatively large effects of year, barrier, and fork length on the model predictions. The fitted SJR inflow model for this reach was

$$
\begin{aligned}
\operatorname{logit}\left(S_{y b i}\right)=\hat{\beta}_{0 y}+0.582(\widehat{\mathrm{SE}}= & 0.238) I_{b}+0.012(\widehat{\mathrm{SE}}=0.004) L_{i} \\
& +1.000(\widehat{\mathrm{SE}}=0.191) \ln \left(\mathrm{SJR} . \text { hor }_{i}\right)
\end{aligned}
$$

where $\hat{\beta}_{0 y}$ ranged from $-12.485(\widehat{\mathrm{SE}}=2.224)$ for 2011 to $-10.617(\widehat{\mathrm{SE}}=$ 1.647) for 2015. Survival from the head of OR to Chipps Island was predicted to be higher for higher levels of SJR inflow as represented by the 5-day mean daily average (Fig. 7), when the barrier was installed at the head of OR, and for larger individuals. Different years were predicted to have different magnitudes of survival for the same Delta inflow levels, consistent with the release-level survival estimates. For example, survival was modeled to be lower in 2014 compared to 2016 for the same levels of SJR inflow when the barrier was in place (Fig. 7). However, 2016 predictions without the barrier were comparable to 2014 predictions with the barrier for the same inflow levels, indicating that the barrier can help to offset noninflow factors that may lower overall survival. While estimated survival was generally higher in 2011 than in either 2014 or 2016 (Table 4; Fig. 6), the regression model indicates that only part of that increase in survival was associated with the high Delta inflow values observed in 2011; the highest predicted survival in 2016 (approximately 0.61) was greater than the majority of the survival predictions for 2011 (0.41-0.68) (Fig. 7).

\section{Survival: head of Old River to the Turner Cut Junction}

Of the 2515 tags detected in the SJR route at the head of OR (SJL telemetry station), 1914 were also detected at the TCJ telemetry stations (MAC or TRN). Travel time from SJL to the TCJ stations ranged from 0.4 to 25.5 days (median $=2.4$ days), and survival estimates in this reach ranged from 0 (March 2013) to $0.92(\widehat{\mathrm{SE}}=0.02$, March 2011) (Table 4). Cumulative survival curves showed that survival in this reach declined most sharply between the head of OR and Garwood Bridge (SJG) in four of the six years (2013-2016) (Fig. 6).

The estimated probability of tag survival to TCJ was $\geq 0.998$ for all study years, so no adjustment for tag failure was included in the survival and detection regression model. The estimated probability of detection at the TCJ telemetry stations (MAC and TRN) was $\geq 0.98$ for 33 of 36 estimates (Table 4). The lowest estimate of detection probability was $0.58(\widehat{\mathrm{SE}}=0.11)$, for the TRN telemetry station for the April 2012 release group (Table 4).

Regression modeling of the joint probability of survival and detection found a highly significant year effect $(P<0.0001)$ and a moderately significant barrier effect after adjusting for year $(P=0.0342)$. The effect of fork length at tagging was not significant $(P=0.1005)$ but was retained in the baseline model for comparison 
Fig. 6. Cumulative survival from Mossdale (MOS) to Chipps Island (CHP) along the San Joaquin River (SJR) route. HOR = Head of Old River $(\mathrm{OR}), \mathrm{SJG}=$ San Joaquin at Garwood Bridge, and TCJ = Turner Cut Junction. Release-specific estimates are lightly shaded and annual estimates (weighted averages of release-specific estimates) are bolded. Intervals are $95 \%$ confidence intervals for annual estimates. Spacing on the horizontal axis is scaled to migration distance. [Colour online.]

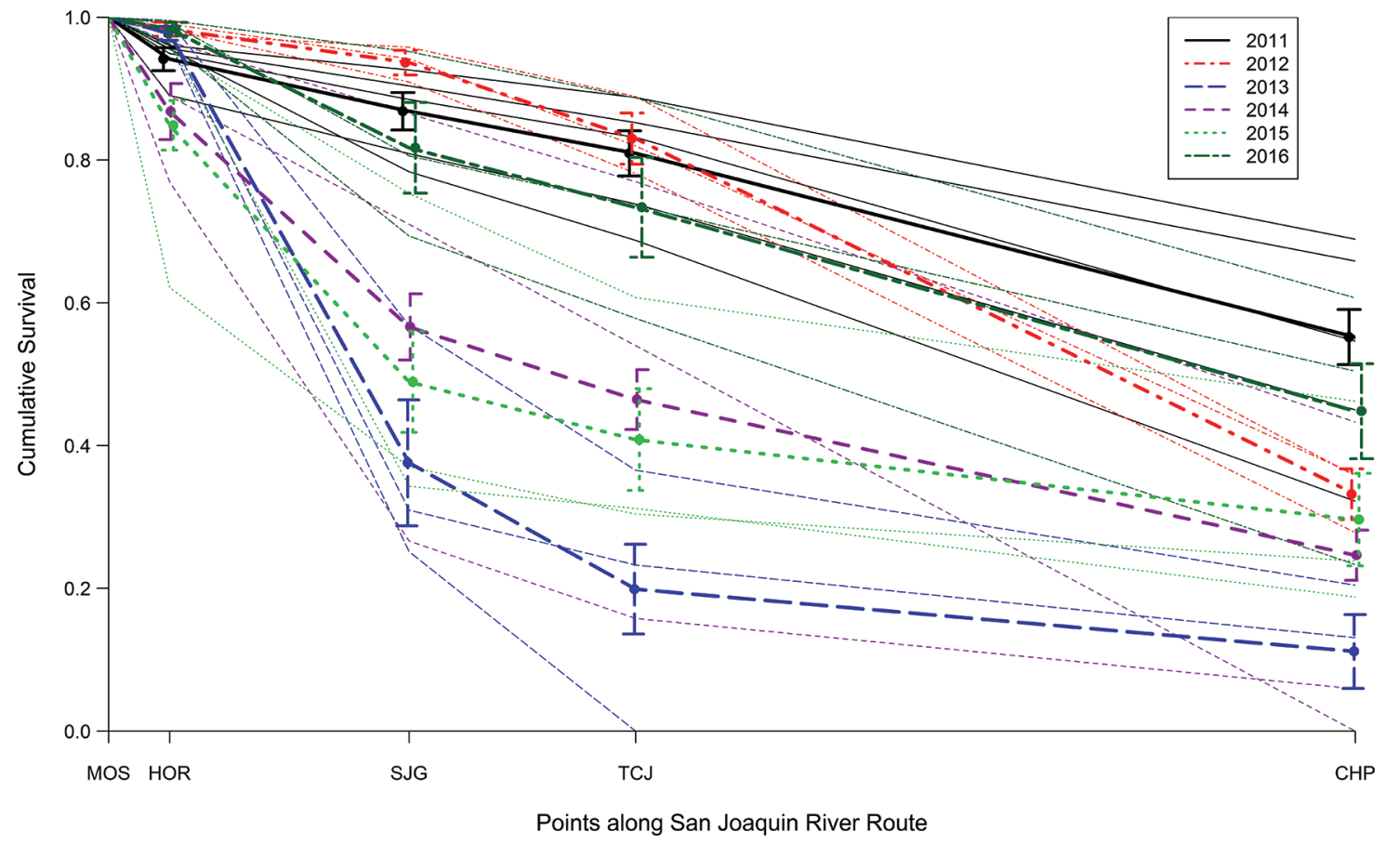

Table 5. Single-variate regression results for survival from the head of Old River (SJL or ORE) to Chipps Island (CHP), tested against the baseline model that adjusted for fixed year effects (2011-2016), barrier effects, and fork length at tagging.

\begin{tabular}{|c|c|c|c|c|c|c|}
\hline Covariate & Name & Type & Sign & $P$ & $\triangle \mathrm{AIC}$ & $\mathrm{AUC}$ \\
\hline SJR.hor & SJR inflow & Delta inflow & + & $<0.0001$ & 0 & 0.72 \\
\hline Tmsd.hor & Temperature at MSD & Temperature & - & $<0.0001$ & 31.87 & 0.72 \\
\hline Tclc.hor & Temperature at CLC & Temperature & Mixed & 0.0001 & 38.12 & 0.72 \\
\hline IE.hor & I:E Ratio & I:E Ratio & + & 0.0008 & 68.18 & 0.71 \\
\hline X2.hor & $\mathrm{X} 2$ & Salinity & - & 0.0016 & 73.21 & 0.71 \\
\hline OMT.hor.net & Mean net OMT flow & Mid-Delta flow & + & 0.0054 & 78.70 & 0.71 \\
\hline SR.hor & SR inflow & Delta inflow & + & 0.0121 & 84.20 & 0.71 \\
\hline pCVP.hor & CVP proportion of exports & Exports & + & 0.0196 & 89.35 & 0.71 \\
\hline SWP.hor & SWP exports & Exports & - & 0.2228 & 104.37 & 0.70 \\
\hline [Baseline] & & & & & 108.76 & 0.70 \\
\hline CVP.hor & CVP exports & Exports & + & 0.4868 & 109.42 & 0.70 \\
\hline CVPSWP.hor & CVP-SWP exports & Exports & - & 0.6375 & 109.55 & 0.70 \\
\hline OMT.hor.rms & RMS of OMT flow & Mid-Delta flow & + & 0.9085 & 124.93 & 0.70 \\
\hline
\end{tabular}

Note: $P$ values result from $F$ tests and should be compared to a testwise $\alpha=0.0042$ for an experimentwise $\alpha=0.05$. See Table 3 for definitions of covariates. Sign refers to the estimated regression coefficient. AUC = area under the curve for the Receiver Operating Characteristic curve.

with other spatial scales. The effect of time of day at SJL was not significant $(P=0.7276)$ and was omitted from the model. The baseline model included effects of year, barrier, and fork length.

Single-covariate regression models found significant interactions between barrier and the CVP and combined CVP-SWP export rates (testwise $\alpha=0.0045 ; \mathrm{P} \leq 0.0012$ ); there was a positive association between exports and survival when the barrier was in place $(P \leq 0.0007)$ and no association when the barrier was absent $(P \geq 0.2221)$. The effects of other covariates were not associated with the barrier $(P \geq 0.0738)$. After adjusting for year, barrier, and fork length effects, SJR inflow accounted for the largest source of variability in the joint probability of survival and detection at the TCJ telemetry stations $(P<0.0001, \triangle$ AIC $\geq 61.64$; Table 6). SJR flow at BDT, the I:E ratio, 7DADM temperature at MSD, and the CVP export rate also accounted for a statistically significant amount of variability $(P \leq 0.0010$ vs. testwise $\alpha=0.0045)$.
Additionally, the combined CVP-SWP export rate, the $\mathrm{X} 2$ measure of salinity, and the CVP proportion of combined exports all had significant effects at the testwise 0.05 level $(P \leq 0.0232)$. When SJR inflow was accounted for, no other covariates had significant added effects $(P \geq 0.1161)$. The effect of SJR inflow was not associated with the barrier presence $(P=0.7524)$, and the main effect of the barrier was no longer significant when inflow was included in the model $(P=0.1146)$. When the model was fitted without the two release groups that had low $(<0.95)$ probability of detection at the MAC or TRN telemetry stations, the same model structure for the SJR inflow model was selected. Alternative models that used the I:E ratio or the CVP export rate in place of SJR inflow also required MSD temperature (I:E and CVP models) and barrier status (CVP model). Among the SJR inflow, I:E ratio, and CVP models, the SJR inflow model was most supported by the data $(\triangle \mathrm{AIC} \geq 26.2)$ and had $\mathrm{AUC}=0.74$ compared to the 
Fig. 7. Predicted probability and $95 \%$ confidence band of surviving from the head of Old River (SJL or ORE stations) to Chipps Island (CHP station) as a function of the 5-day average daily Delta inflow from the San Joaquin River (SJR) measured at Vernalis, for model: $\operatorname{logit}\left(S_{y b i}\right)=\hat{\beta}_{0 y}+0.582(\widehat{\mathrm{SE}}=0.238) I_{b}+0.012(\widehat{\mathrm{SE}}=0.004) L_{i}+1.000(\widehat{\mathrm{SE}}=0.191) \ln \left(\mathrm{SJR}\right.$. hor $\left._{i}\right)$. Results are shown using 2011, 2014, and 2016 intercepts: $\hat{\beta}_{0,2011}=-12.485(\widehat{\mathrm{SE}}=2.224), \hat{\beta}_{0,2014}=-11.612(\widehat{\mathrm{SE}}=1.806)$, and $\hat{\beta}_{0,2016}=-10.988(\widehat{\mathrm{SE}}=1.840)$. Model predictions were fit for the average fork length at tagging, $245 \mathrm{~mm}$.

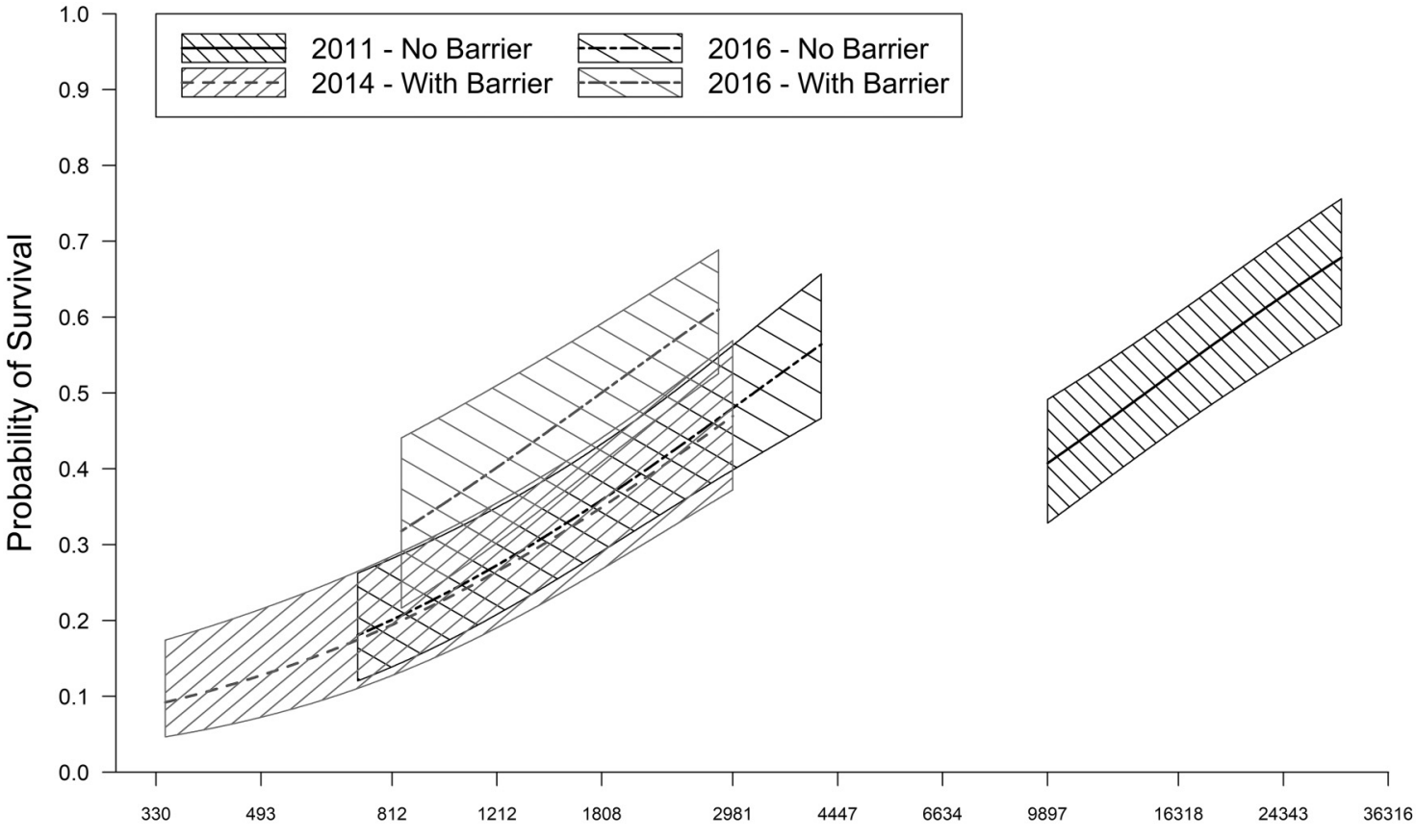

5-Day Average Daily SJR inflow from HOR detection [cfs]

Table 6. Single-variate regression results for the joint probability of survival from the head of Old River (SJL) to the Turner Cut Junction (TCJ; MAC or TRN) and detection at TCJ, tested against the baseline model that adjusted for fixed year effects (2011-2016), barrier effects, and fork length at tagging.

\begin{tabular}{|c|c|c|c|c|c|c|c|}
\hline Covariate & Name & Type & Sign & $P$ & $\Delta \mathrm{AIC}$ & AUC & Barrier $\times \mathrm{X}$ \\
\hline SJR.hor & SJR inflow & Delta inflow & + & $<0.0001$ & 0.00 & 0.74 & No \\
\hline BDT.hor.net & Mean Net BDT flow & Flow & + & $<0.0001$ & 61.64 & 0.73 & No \\
\hline IE.hor & I:E Ratio & I:E Ratio & + & $<0.0001$ & 80.54 & 0.73 & No \\
\hline Tmsd.hor & Temperature at MSD & Temperature & - & $<0.0001$ & 85.45 & 0.71 & No \\
\hline CVP.hor & CVP exports & Exports & Mixed & 0.0010 & 115.78 & 0.69 & Yes \\
\hline CVPSWP.hor & CVP-SWP exports & Exports & Mixed & 0.0051 & 131.07 & 0.69 & Yes \\
\hline X2.hor & $\mathrm{X} 2$ & Salinity & - & 0.0162 & 133.56 & 0.71 & No \\
\hline pCVP.hor & CVP proportion of exports & Exports & + & 0.0232 & 134.23 & 0.71 & No \\
\hline OMT.hor.net & Mean net OMT flow & Mid-Delta flow & + & 0.0932 & 142.08 & 0.69 & No \\
\hline SWP.hor & SWP exports & Exports & - & 0.1966 & 147.17 & 0.70 & No \\
\hline OMT.hor.rms & RMS of OMT flow & Mid-Delta flow & - & 0.3791 & 151.78 & 0.68 & No \\
\hline [Baseline] & & & & & 153.58 & 0.70 & \\
\hline
\end{tabular}

Note: $P$ values result from $F$ tests and should be compared to a testwise $\alpha=0.0045$ for an experimentwise $\alpha=0.05$. See Table 3 for definitions of covariates. Sign refers to the estimated regression coefficient. AUC = area under the curve for the Receiver Operating Characteristic curve. Barrier $\times \mathrm{X}$ indicates whether the model included an interaction effect between the covariate and barrier status.

baseline AUC of 0.70. The simulated bias calculations found a mean relative bias in regression parameters of $4 \%$ for the SJR inflow model due to imperfect detection, compared to $113 \%$ for the I:E model and 67\% for the exports model. Thus, the inflow model was preferred over alternative models.

The fitted SJR inflow model was

$$
\begin{aligned}
\operatorname{logit}\left(\mathrm{SP}_{y i}\right)=\hat{\beta}_{0 y}+0.016(\widehat{\mathrm{SE}} & =0.006) L_{i} \\
& +1.751(\widehat{\mathrm{SE}}=0.290) \ln \left(\mathrm{SJR} \text { hor }_{i}\right)
\end{aligned}
$$

where $\hat{\beta}_{0 y}$ ranged from $-19.2816(\widehat{\mathrm{SE}}=3.3882)$ for 2011 to -15.4221 $(\widehat{\mathrm{SE}}=2.5744)$ for 2015. An increase in SJR inflow from 800 to
$1400 \mathrm{cfs}$ was associated with a modeled increase in SP from 0.11 $(\widehat{\mathrm{SE}}=0.06)$ to $0.25(0.10)$ in 2013 , and from $0.59(0.09)$ to 0.79 (0.07) in 2015 (Fig. 8).

\section{Survival: Turner Cut Junction to Chipps Island}

Of the 1914 tags detected at the TCJ telemetry stations (MAC or TRN), 1104 were subsequently detected at either CHP or BBR. Travel time from TCJ to Chipps Island ranged from 0.9 to 30.5 days (median $=3.0$ days). Route-specific survival estimates in this region ranged from 0 (May 2013) to $0.94(\widehat{\mathrm{SE}}=0.06$, April 2015), and tended to be higher in the SJR route (0.34-0.94) than in the TC route (0-0.69) (Table 4). Survival estimates were unavailable for some release 
Fig. 8. Predicted probability and $95 \%$ confidence band of surviving from the head of Old River (SJL station) to the Turner Cut Junction (TCJ) and detection at MAC or TRN stations as a function of the 5-day average daily Delta inflow from the San Joaquin River measured at Vernalis, for model: $\operatorname{logit}\left(\mathrm{SP}_{y i}\right)=\hat{\beta}_{0 y}+0.016(\widehat{\mathrm{SE}}=0.006) L_{i}+1.751(\widehat{\mathrm{SE}}=0.290) \ln \left(\mathrm{SJR}_{\mathrm{f}} \mathrm{hor}_{i}\right)$. Results are shown using 2011, 2013, and 2015 intercepts: $\hat{\beta}_{0,2011}=-19.282(\widehat{\mathrm{SE}}=3.388), \hat{\beta}_{0,2013}=-17.849(\widehat{\mathrm{SE}}=2.749)$, and $\hat{\beta}_{0,2015}=-15.422(\widehat{\mathrm{SE}}=2.574)$. Model predictions were computed for the average fork length at tagging for fish in this analysis, $248 \mathrm{~mm}$.

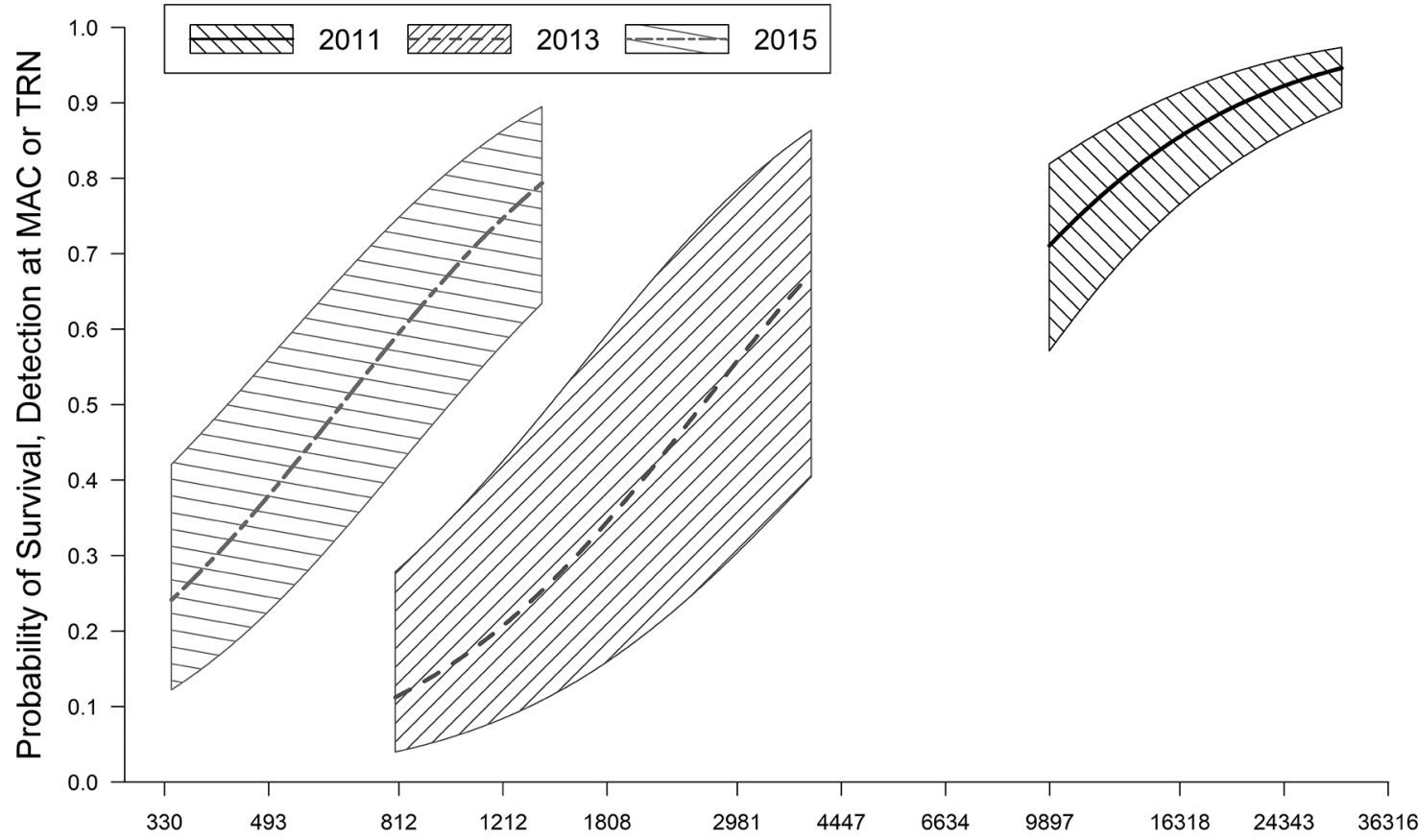

5-Day Average Daily SJR inflow from HOR detection [cfs]

groups because of low survival to TCJ (i.e., March 2013, May 2014, early March 2015; Table 4). Route selection probability estimates for the TC route ranged from $0.09(\widehat{\mathrm{SE}} \leq 0.04$; March 2011, late March 2015) to $0.50(\widehat{\mathrm{SE}}=0.09$, June 2011) (Table S1, Supplemental Material $\left.{ }^{1}\right)$.

Survival and detection modeling used the same detection probability model structure as from the head of OR to Chipps Island. The effect of migration route (SJR vs. TC) was highly significant in accounting for variation in survival to Delta exit $(P<0.0001)$; year was also significant $(P=0.0192)$. Barrier at the head of $O R$ and time of day at TCJ were not significant $(P \geq 0.4194)$ and were omitted from the survival model. Fork length at time of tagging was significant at the $10 \%$ level $(P=0.0945)$; although not strongly significant, fork length was retained in the model for comparability with other spatial scales. When year, route, and fork length were all accounted for, no other covariate was associated with survival to Chipps Island $(P \geq 0.2283)$. The baseline model that adjusted for year, route, and fork length had an AUC value of 0.75 , indicating good model fit without any other covariates; the added effects of covariates increased the AUC by no more than 0.01 . The model estimated that remaining in the SJR increased the probability of survival from TCJ to Chipps Island by $0.29(\widehat{\mathrm{SE}}=0.04)$ to $0.44(\widehat{\mathrm{SE}} \leq$ 0.07), depending on the year and fish length (e.g., Fig. 9).

\section{Drought effects}

Comparisons of survival estimates with drought status found a significant association between drought and survival from the head of OR to Chipps Island in the OR route $(P<0.0001)$ but not in the SJR route $(P=0.1458)$. Average survival across release groups in the OR route was $0.17(\widehat{\mathrm{SE}}=0.01)$ during the drought years (2013-2015) and $0.36(0.02)$ during the non-drought years (2011, 2012, and 2016). The drought effect in the OR route persisted when the barrier was not in place $(P=0.0005)$ and when 2011 was excluded from analysis $(P=0.0034)$. In the SJR route, there was a difference in survival from the head of OR to TCJ based on drought status $(P=0.0276)$; average survival was $0.44(0.03)$ during the drought years and $0.82(0.01)$ during the non-drought years. There was no significant difference in survival from TCJ to Chipps Island between drought and non-drought years in either route $(P \geq 0.3309)$. Visual inspection of cumulative survival curves found higher per-km mortality rates upstream of TCJ in the drought years compared to non-drought years (Fig. 6). GLM models that replaced year-specific intercepts with drought-specific intercepts (two-way classification) or water-year-specific intercepts (three-way classification) fit considerably more poorly than the year-effects model on all three spatial scales $(P \leq 0.0106)$.

\section{Discussion}

The broad challenges faced by steelhead emigrating through the SR-SJR Delta are representative of those faced by salmonids in estuaries of other river systems. The combination of habitat loss, reduced river flows, increased resource use, warming temperatures, and non-native aquatic community structure is intensified in the SJR Delta by its southern latitude in the steelhead range and by human development of the region. Other populations are soon likely to face comparable challenges as a result of climate change, growing population density, and expanded modification of estuary habitat (Magnusson and Hilborn 2003; Moyle et al. 2008). Studies of both Pacific salmonids and Atlantic salmon (Salmo salar) demonstrate that survival of juvenile salmonids tends to be lower and more variable in estuaries than in either river or marine habitats (Welch et al. 2011; Thorstad et al. 2012). Thus, understanding estuarine survival is of paramount importance to population persistence. This study was the first to yield a 
Fig. 9. Predicted probability and $95 \%$ confidence band of surviving from Turner Cut Junction (TCJ) to Chipps Island as a function of fork length at tagging and route selection, for model: $\operatorname{logit}\left(S_{y r i}\right)=\hat{\beta}_{0 y}-1.895(\widehat{\mathrm{SE}}=0.125) \mathrm{I}_{r}+0.011(\widehat{\mathrm{SE}}=0.003) L_{i}$. Results are shown using 2011 and 2012 intercepts: $\hat{\beta}_{0,2011}=-1.542(\widehat{\mathrm{SE}}=1.620)$ and $\hat{\beta}_{0,2012}=-2.499(\widehat{\mathrm{SE}}=1.374)$.

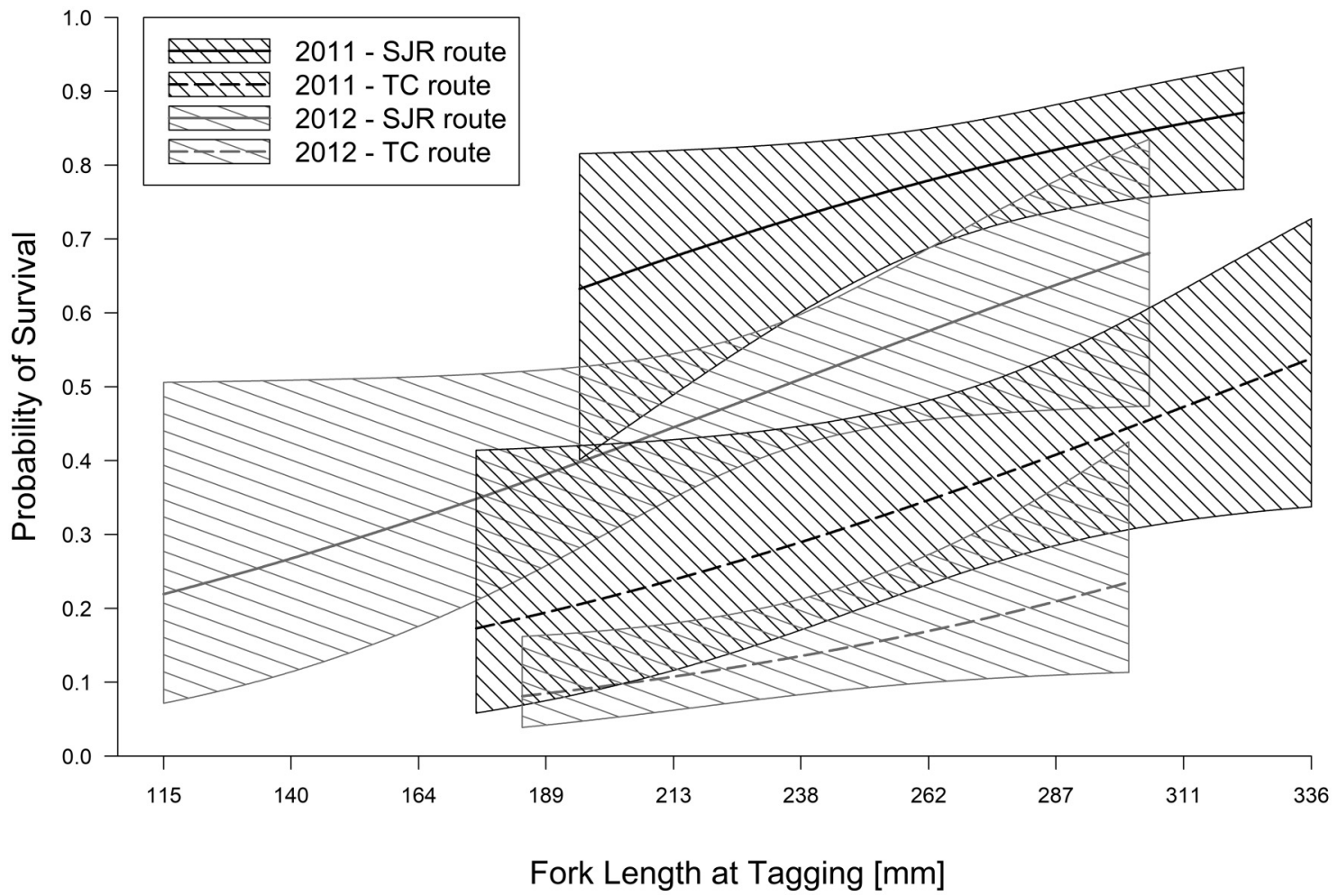

multi-year time series of spatially detailed steelhead estuarine survival estimates and has demonstrated that survival varies considerably spatially, between years, and seasonally through this inland estuary. This level of variability would not have been apparent from a study shorter in duration. Despite the effort required to estimate estuarine survival, multi-year time series are necessary to represent the variability in conditions and survival experienced by steelhead populations in these environments.

This study presents the first direct estimates of survival of CV steelhead as they emigrate from the SJR through the SR-SJR Delta. The few previous CV steelhead survival studies focused on steelhead emigrating from the SR, representing the northern components of the CV Evolutionarily Significant Unit, and presented results from only single study years or for only broad spatial areas (Singer et al. 2013; Brodsky et al. 2020; Sandstrom et al. 2020). Historically, management approaches for SJR steelhead have been geared toward Chinook salmon rather than steelhead patterns of migration and habitat use, and steelhead survival has been inferred from adult escapement and CWT data from salmon (McEwan 2001). These acoustic-telemetry estimates show that steelhead survival through the Delta varies considerably both between and within years: release-level survival estimates from Mossdale to Chipps Island varied from 0.06 to 0.69 (Table 4). These survival levels are more variable and often considerably higher than those observed for fall-run Chinook Salmon migrating through the same regions at similar times, which were consistently $\leq 0.05$ for 2011-2014 (Buchanan et al. 2015, 2018). However, these steelhead survival estimates were comparable to or lower than those reported for SR steelhead and late fall-run Chinook salmon migrating through the Delta from the north only a few months earlier in mid- to late-winter (Singer et al. 2013; Perry et al. 2013; Michel et al. 2015; Sandstrom et al. 2020). The temporal and spatial variation in survival across the CV demonstrates the continuing need for acoustic telemetry studies using relevant populations of juvenile salmonids to understand potential ecological processes and management strategies linked to survival, rather than inferring these measures from past studies or different basins.

Although monitoring the performance of imperiled populations is preferred for their management, studying such populations is often difficult. Regulations and small population sizes may prevent collection of individuals from protected species and individuals suitable for tagging may represent only larger size classes or late juvenile life stages. In this study, we used yearling hatchery fish from MRFH to represent steelhead emigrating from the SJR basin. Although MRFH steelhead are included in the threatened CV DPS and this hatchery is in the SJR basin, the SJR steelhead that emigrate past our release site are naturally produced rather than hatchery fish. Differences have been found in survival patterns between wild and hatchery salmonids in the Columbia River basin and may exist between the hatchery and wild components of the CV DPS as well (Buchanan et al. 2010; Murphy et al. 2011). Nevertheless, we believe that hatchery steelhead provide better inference than hatchery Chinook Salmon, which have otherwise been the basis for management of SJR steelhead. Other considerations include tag size, which may limit the individuals available for study, and tag effects on survival performance. This study used multiple strategies to limit or eliminate tag effects, and we recommend the same for future studies. Additionally, increased monitoring of juvenile steelhead exiting upstream tributaries would facilitate characterization of the proportion of run-of-river emigrants represented by the tagged fish.

Management strategies designed to support steelhead survival in the Delta have included keeping fish out of the OR route, releasing water from upstream reservoirs to increase river inflow to the Delta, and limiting water pumping rates at the export facilities in the spring when the fish are migrating. The I:E ratio has been used as a regulatory metric to moderate water export rates and Delta inflow. The results in this study provide a look at 
how consistent actual steelhead survival patterns are with these management strategies and demonstrate agreement with some expected patterns but not others. Estimated survival was higher when the barrier was in place at the head of OR and when Delta inflow and the I:E ratio were higher, as expected. However, survival was not notably higher in the SJR route compared to the OR route or for lower export rates, contrary to expectations. Furthermore, different survival processes were apparent in adjacent habitats, indicating that actions to support survival should also be spatially defined.

The lack of a consistent route-specific survival difference between the SJR and OR routes was surprising, considering that both water export facilities are located in the OR route. Although the point estimates of survival were higher for the SJR route compared to the OR route for 16 of 19 release groups (Table 4), the differences were sometimes very small and were not statistically significant when adjusted for year, barrier status, and fork length $(P=0.1282)$. The barrier affects route selection at the head of OR by blocking most access to the OR route, so it is possible that the perceived barrier effect was at least partially a route effect: if the SJR route is superior and the barrier directs fish into that route, then the barrier effect would be positive. If this were true, then a route effect should be observed whether or not the barrier was present. However, the withinyear difference between annual route-specific survival estimates was close to $0(-0.04$ to 0.03$)$ for years without the barrier and ranged up to 0.27 for years when the barrier was installed. Additionally, the barrier effect was significant even when route was accounted for $(P=0.0207)$, and AIC was lower for a barrier model over a route model $(\triangle \mathrm{AIC}=15.3)$. These results suggest that perceived survival differences between the routes were primarily due to the presence of the temporary rock barrier. The fact that survival was not associated with route further suggests that it was the barrier's influence on hydrodynamic conditions in the SJR that contributed to higher survival by diverting SJR inflow away from OR and into the lower SJR. Likewise, the survival modeling for the SJR route upstream of the TCJ suggests that survival benefits in this reach can be attained either by increasing Delta inflow or by installing the barrier. The mechanical nature of the barrier's action, i.e., diversion of both fish and water, lends support to the hypothesis that the perceived survival differences associated with the barrier are due to the barrier's physical presence rather than to other, unacknowledged variables (e.g., season). Discontinuation of barrier use in future years may have a negative effect on steelhead survival in the Delta unless additional management strategies are implemented to direct both fish and flow into the SJR, such as modifying hydrodynamics or channel morphology in the head of OR region.

This work represented the OR route effect as a difference in total survival probability to Chipps Island in the OR route compared to the SJR route. This is reasonable for identifying factors associated with overall fish fate in this region (successfully leave the Delta vs. mortality in the Delta). An alternative assessment of route effects would explore the relative differences in survival rate per kilometre rather than total survival probability, i.e., $\sigma=S^{1 / d}$ for route length $d$. Because different routes have different lengths, a route effect on the survival rate scale may not be apparent on the total survival scale. A similar consideration applies to daily survival rate. A difficulty in modeling survival rate rather than total survival probability is identifying a well-defined migration route distance: both the OR and SJR routes from the head of OR include multiple subroutes of varying lengths. In the OR route, the migration pathway from the head of OR to Chipps Island is approximately $45 \mathrm{~km}$ via the salvage subroutes (omitting distance trucked) but is $88 \mathrm{~km}$ via OR itself (bold line in Fig. 1c). In the SJR route, the total migration pathway is approximately $88 \mathrm{~km}$ via the mainstem SJR compared to up to $100 \mathrm{~km}$ via the salvage facilities, depending on routing choices at TCJ and throughout the interior Delta (Fig. 1b). We performed a preliminary survival rate analysis using an OR route length weighted toward the salvage subroutes $(\mathrm{km}=55)$ and a SJR route length representing non-salvage subroutes $(\mathrm{km}=88)$. Using these route lengths to define survival rate per kilometre, we found a significant negative effect of the OR route on the survival rate $(P<0.0001)$, suggesting more intense mortality forces in the OR route. This is consistent with expectations that the OR route is more treacherous but is highly sensitive to the migration route lengths assumed in analysis and appears to have been largely offset by the actual pathway lengths experienced by the study fish in the OR and SJR routes when considering total survival probability to Delta exit. Future work will investigate the migration route distances more fully and the potential effect of routing choices on survival in and through the Delta.

The relationship between SJR inflow and survival was particularly strong and, together with year, barrier status, and fork length, accounted for all the variation in survival that was associated with other environmental and operational covariates. The positive relationship between SJR inflow and survival translated to a positive relationship between the I:E ratio and survival as well. Several mechanisms may contribute to the positive relationship observed between inflow and survival. One possibility is that higher flows result in faster water velocities and shorter travel times, so that fish are at risk of mortality in the study area for a shorter period of time (Anderson et al. 2005). Travel time was negatively associated with SJR inflow in the tidal transitional reach from the head of OR to the TCJ $(P=0.0001)$, where there was also a positive relationship between SJR inflow and survival, consistent with this hypothesis. However, travel time was also negatively associated with SJR inflow in the tidal reach between TCJ and Chipps Island $(P=0.0363)$, where survival was unrelated to inflow. This heterogeneous spatial pattern is consistent with findings in Perry et al. (2018) for the northern Delta. Alternatively, higher flows are associated with lower temperatures, higher levels of dissolved oxygen, and lower levels of contaminants (Sinokrot and Gulliver 2000; Monsen et al. 2007; Grossman 2016), all of which may influence survival. It is likely that more than one mechanism accounts for the inflow-survival relationship observed.

Despite the strong findings for Delta inflow, there were limitations to the dependence of survival on inflow. The first year of the study, 2011, was a high flow year and had daily inflow values that were 1.5 to 91 times the inflow observed in the other five years of the study (Fig. 3). Nevertheless, some release groups from 2011 had survival estimates that were comparable to or lower than those seen in drier years (Table 4). The high flow in 2011 prevented installation of the barrier at the head of OR; it appears that the barrier may help mitigate for effects of low flows in drier years (Fig. 7). Additionally, the inflow-survival relationship was notably absent in the region between the TCJ and Chipps Island. The region downstream (i.e., north and west) of the TCJ is strongly tidally dominated, and it is reasonable that environmental conditions there are largely insensitive to SJR inflow from $>50 \mathrm{rkm}$ upstream. Additional management strategies beyond reservoir releases and the head of OR barrier will be needed to improve survival in this region.

Current management strategies assume that survival is lower when Delta exports are higher, in particular because of the increased risk of migration delay at the facilities or entrainment at the pumps. There is also thought to be a large population of predators in and within close proximity to the facilities (Grossman 2016; Moyle et al. 2017). Nevertheless, this study found no association between export rate and survival from the head of OR to Chipps Island $(P \geq 0.2228$; Table 5). There was weak support for an association between survival and the CVP proportion of combined exports (pCVP; $P=0.0196)$, which measures the allocation of exports across the two large export facilities; even this evidence was inconclusive, however, given the large number of covariates considered. On the other hand, we observed a positive association between export 
rate and survival in the SJR main stem upstream of the TCJ when the barrier was in place. This was surprising because fish in this reach are not near the export facilities and hydrodynamics models have found little effect of exports on flow and velocity patterns in this region (Cavallo et al. 2013). However, export rate and Delta inflow tend to be positively correlated (partial correlation coefficient $=0.56, P<0.0001$, after adjusting for year with the barrier in place) and survival was more strongly associated with SJR inflow than with exports in this reach, so the association between exports and survival in the SJR main stem may result from an inflow effect rather than causal export effects. Overall, we recommend that the export rate results be viewed in the context of existing policy, which uses the I:E ratio regulatory metric to dictate restricted export levels during the spring outmigration and thus low variability in export levels during the tagging study. For example, during the study period each year, mean daily combined (CVP+SWP) export levels were $\leq 6100 \mathrm{cfs}$, compared to values up to $12862 \mathrm{cfs}$ during the full 2011-2016 water years (October to September). The relatively low variability in export levels in this study makes it difficult to detect potential survival effects; it is conceivable that different survival patterns might be exhibited under unrestricted (i.e., higher) exports, especially in the OR route which passes the entrances to the pumping facilities. For these reasons, the assessment of exports reported here should not be interpreted as a complete assessment of the policy that defines allowable export operations in the spring but rather an assessment of the variability in exports actually observed in the springs of 2011-2016.

The survival patterns observed in relation to the barrier and to some extent exports help explain the surprisingly high throughDelta survival observed in the extreme drought year of 2015 (Table 5). Of the six years in the study, 2015 had the lowest inflow, highest temperatures, and highest X2 (salinity) levels (Fig. 3). Despite the harsh conditions, the overall estimated probability of survival from Mossdale to Chipps Island in 2015 (0.23) was considerably higher than for $2013(0.14)$, which was also a drought year but had higher inflow, slightly lower temperatures, and lower $\mathrm{X} 2$. However, export levels were lower and less variable in the 2015 study (mean $1765 \mathrm{cfs}$ ) than in the 2013 study (mean = $2464 \mathrm{cfs}$; Fig. 4), and the barrier was installed for the majority of 2015 but not in 2013. Average fork length at tagging was also higher in $2015(235 \mathrm{~mm})$ than in $2013(212 \mathrm{~mm})$. Survival in the SJR route was considerably higher in 2015 than in 2013, and it was also higher than in the OR route in 2015 , consistent with a positive barrier effect. Comparison of these years demonstrates the potentially mitigating effects of fish size, the head of OR barrier, and lower exports in very low flow years. Although these factors are insufficient to fully compensate for lack of water entering the Delta, they may help prevent very low survival that could lead to further declines in anadromous 0 . mykiss abundance.

Despite the lack of route-specific survival differences from the head of OR to Chipps Island, there was a strong survival difference between the mainstem (SJR) route and the interior Delta (TC) route from the TCJ $(P<0.0001)$. Remaining in the SJR route at TCJ was estimated to increase the survival probability to Chipps Island by up to 0.44 (Fig. 9). This finding is similar to observations that late-fall-run Chinook salmon and steelhead migrating from the SR had lower survival in interior Delta routes than in mainstem river routes (Perry et al. 2010; Singer et al. 2013). The interior Delta connects the mainstem river to the water export facilities located in the SW Delta, and one hypothesis is that entering the interior Delta at the TCJ lowers survival by increasing the risk of entrainment at the facilities; entrained fish that are salvaged may appear at Chipps Island as successful Delta migrants, but those that are not salvaged are lost to the pumps, water conveyance canals, or predation and appear as mortalities in the statistical models. Indeed, of the 489 steelhead detected entering TC, $135(28 \%)$ were subsequently detected at the water export facility entrances, compared to $5 \%$ of the 1451 fish using the SJR mainstem route from the TCJ. However, the route with the highest proportion of fish entering the facilities was the OR route: $67 \%$ of the fish in that route, compared to only $8 \%$ of the fish that chose the SJR route at the head of OR. If increased entrainment was the source of the reduced survival in the TC route, then we would also expect to see markedly lower survival in the OR route compared to the SJR route from the head of OR. This was not observed. Another possibility is that the habitat in the interior Delta results in higher mortality risk compared to the mainstem river. The TC route leads fish to the central portion of the interior Delta, which is also the region encountered by SR salmon that enter the interior Delta. This region includes several submerged islands that have low water velocities, low turbidity, dense mats of non-native vegetation such as Brazilian waterweed (Egeria densa), and populations of non-native, warm-water predatory fish such as largemouth bass (Nobriga and Feyrer 2007; Conrad et al. 2016). Although the late-fall-run Chinook salmon from the SR studies migrate through the region in winter when predation rates are expected to be lower compared to this study's spring steelhead migration, the lake-type habitat common in the central region of the interior Delta may pose similar challenges to both populations of migrating salmonids. Preventing fish from entering the interior Delta at TC is challenging because the hydrodynamics in the junction do not allow for a barrier to be installed, and fish may enter the interior Delta through multiple routes from further downstream. Instead, management strategies to improve habitat in the interior Delta for native fish and make it less desirable for non-native predators may have the potential to increase survival in this region for salmonids migrating from both the SJR basin and the SR basin.

Precipitation patterns in California are projected to be more volatile under climate change, with more frequent and extreme droughts and also more extreme flood events (Dettinger 2011; Diffenbaugh et al. 2015; Swain et al. 2018), and one question managers face is how mitigation strategies may be affected by drought. This study showed evidence of a drought effect on steelhead survival through the Delta, in particular in the OR route and in the SJR downstream to the TCJ; survival through these regions tended to be higher in non-drought years. However, investigation efforts were hampered by the large differences in flow among the non-drought years, in particular between 2011 (wet year) and the dry years of 2012 and 2016. Although both drought status and water year status varied by year, neither criterion fully accounted for the year effects in the survival models. This result hinders efforts to predict survival as a function of drought status without better understanding of the factors that drive year effects.

Drought may affect survival patterns in the Delta in several ways, including lowering inflows and increasing temperatures. One mechanism by which drought may affect survival is to move the location of the zone where the habitat transitions from unidirectional flow to bidirectional tidal flows. This transition zone and its dependence on Delta inflow may be critical to the relationship between inflow and survival (Perry et al. 2018). A shift of that transition zone farther upstream during drought would introduce migrating salmonids to reverse flows and altered water quality factors earlier in their migration. In the SJR, the transition reach lies between the head of OR and the TCJ most years, depending on inflow conditions and barrier status at the head of OR (Cavallo et al. 2013; National Oceanic and Atmospheric Administration Fisheries Salmon Scoping Team 2017). Because the barrier keeps more river flow in the SJR, it is expected to keep the location of the transition farther downstream even in drought years, and thus may be an important mitigating factor for low inflow during drought. These possibilities are supported by cumulative survival curves from this study, which show that for all three drought years and only one non-drought year, the SJR reach that had the highest mortality rate downstream of the 
head of OR was in the upstream portion of the stretch from OR to the TCJ, specifically from OR to Garwood Bridge (SJG; Fig. 6). The mortality rate to Garwood Bridge was noticeably higher in the drought years than in the wet and dry years and was the highest in 2013, the only drought year without a barrier installed at the head of OR (Fig. 6). Efforts to mitigate effects of drought should include improving habitat for migrating salmonids in this reach as well as either installing the barrier at the head of OR or redesigning channel morphology at that river junction to keep more flow in the SJR. These actions may be especially important to support steelhead populations as climate change affects the frequency of drought and lower seasonal flows.

This study is a step forward in understanding the temporal and spatial variability in survival of CV steelhead populations as they emigrate through the San Joaquin Delta and the factors that affect survival. Although the specific results are unique to this population, a similar degree of spatial and temporal variability may be expected in other estuarine systems. Likewise, the investigative and analytical approaches used in this paper may be employed in other systems to monitor steelhead performance through the crucial estuarine juvenile life stage and inform management strategies to support the anadromous life history. The results here have implications for management designed to support emigrant survival in the Delta, including timing reservoir releases from the multiple SJR tributaries to coincide with the juvenile migration, directing more flow down the SJR rather than $\mathrm{OR}$, and restoring habitat south of TC and in the central interior Delta. There is more work to be done in studying this threatened population, and future tagging studies will provide data for testing the models developed here. Questions for future investigation include the factors driving route selection at various junctions in the Delta, juvenile steelhead residence time and the propensity of Delta rearing, reach-specific flow-survival relationships, survival differences between hatchery and run-of-river steelhead and between steelhead and Chinook salmon, the role of non-native predators and non-native vegetation on survival patterns in different regions of the Delta, and the sensitivity of adult returns to estuarine and early marine survival. Another important management need is estimating steelhead survival further downstream through the bays. Understanding these and other issues will be necessary to support the anadromous component of the CV's 0 . mykiss population and maintain the life history diversity necessary for this population to persist in a changing climate.

\section{Competing interests statement}

The authors declare there are no competing interests.

\section{Contributors' statement}

$\mathrm{RB}$ contributed research ideas, developed the analytical methods, performed the analysis, and was lead author. JI and EB both contributed research ideas, interpretation of results, and assisted in writing.

\section{Funding statement}

This research was supported by the US Bureau of Reclamation (contract No. R11AC20116, R13AC20506, R17AC00042).

\section{Data availability statement}

The data used in this analysis are available upon request from the lead author.

\section{Acknowledgements}

Many individuals from several agencies made this project possible. The tagging studies were directed by the US Bureau of Reclamation (USBR) and the US Fish and Wildlife Service (USFWS).
Individuals from the USFWS, USBR, California Department of Water Resources (CDWR), and the US Geological Survey (USGS) implemented the tagging and release components of the project. The USGS provided training for the surgeons, helped design and installed, maintained, and retrieved the acoustic receiver array, and pre-processed the data. Funding for data analysis and preparation of this article came from the USBR. The authors are grateful to the many people and agencies who funded, oversaw, and implemented fish tagging, care, and release and acoustic receiver installation, maintenance, retrieval, and processing, Craig Scanlan for assistance in preparing the manuscript, Steve Whitlock and Chris Holbrook for assistance in map creation, and two anonymous reviewers for helpful comments on an early draft. The views expressed are those of the authors and represent neither policy nor endorsement by the USBR.

\section{References}

Adams, N.S., Rondorf, D.W., Evans, S.D., and Kelly, J.E. 1998. Effects of surgically and gastrically implanted radio transmitters on growth and feeding behavior of juvenile Chinook Salmon. Trans. Am. Fish. Soc. 127(1): 128136. doi:10.1577/1548-8659(1998)127<0128:EOSAGI >2.0.CO;2.

Anderson, J.J., Gurarie, E., and Zabel, R.W. 2005. Mean free-path length theory of predator-prey interactions: application to juvenile salmon migration. Ecol. Modell. 186(2): 196-211. doi:10.1016/j.ecolmodel.2005.01.014.

Brodsky, A., Zeug, S.C., Nelson, J., Hannon, J., Anders, P.J., and Cavallo, B.J. 2020. Does broodstock source affect post-release survival of steelhead? Implications of replacing a non-native hatchery stock for recovery. Environ. Biol. Fishes, 103: 437-453. doi:10.1007/s10641-020-00951-2.

Buchanan, R.A. 2018a. 2014 six-year acoustic telemetry and steelhead study: statistical methods and results. Technical report to the US Bureau of Reclamation. Available from http://www.cbr.washington.edu/papers.

Buchanan, R.A. 2018b. 2015 six-year acoustic telemetry and steelhead study: statistical methods and results. Technical report to the US Bureau of Reclamation. Available from http://www.cbr.washington.edu/papers.

Buchanan, R.A. 2018c. 2016 six-year acoustic telemetry and steelhead study: statistical methods and results. Technical report to the US Bureau of Reclamation. Available from http://www.cbr.washington.edu/papers.

Buchanan, R.A., and Skalski, J.R. 2020. Relating survival of fall-run Chinook salmon through the San Joaquin Delta to river flow. Environ. Biol. Fishes, 103: 389-410. doi:10.1007/s10641-019-00918-y.

Buchanan, R.A., Skalski, J.R., and Giorgi, A.E. 2010. Evaluating surrogacy of hatchery releases for the performance of wild yearling Chinook Salmon from the Snake River Basin. N. Am. J. Fish. Manage. 30: 1258-1269. doi:10. 1577/M09-175.1.

Buchanan, R.A., Skalski, J.R., Brandes, P.L., and Fuller, A. 2013. Route use and survival of juvenile Chinook Salmon through the San Joaquin River Delta. N. Am. J. Fish. Manage. 33(1): 216-229. doi:10.1080/02755947.2012.728178.

Buchanan, R.A., Brandes, P.L., Marshall, M., Foott, J.S., Ingram, J., LaPlante, D., and Israel, J., 2015. 2012 South Delta Chinook Salmon Survival Study. Edited by P. Brandes. US Fish and Wildlife Service. Available from https://www.fws.gov/ lodi/salmonid_survival_studies/juvenile_salmonid_survival_reports.htm [accessed 4 June 2020].

Buchanan, R.A., Brandes, P.L., and Skalski, J.R. 2018. Survival of juvenile fallrun Chinook salmon through the San Joaquin River Delta, California, 2010-2015. N. Am. J. Fish. Manage. 38(3): 663-679. doi:10.1002/nafm.10063.

Burnham, K.P., and Anderson, D.R. 2002. Model selection and multimodel inference: a practical information-theoretic approach. 2nd ed. Springer, New York.

Cavallo, B., Gaskill, P., and Melgo, J. 2013. Investigating the influence of tides, inflow, and exports on sub-daily flow in the Sacramento-San Joaquin delta. Report prepared by Cramer Fish Sciences. Available from https:/ www.researchgate.net/profile/Bradley_Cavallo/publication/329075645.

Clemens, B.J., Clements, S.P., Karnowski, M.D., Jepsen, D.B., Gitelman, A.I., and Schreck, C.B. 2009. Effects of transportation and other factors on survival estimates of juvenile salmonids in the unimpounded lower Columbia River. Trans. Am. Fish. Soc. 138(1): 169-188. doi:10.1577/T07-090.1.

Cohen, A.N., and Carlton, J.T. 1998. Accelerating invasion rate in a highly invaded estuary. Science, 279(5350): 555-558. doi:10.1126/science.279.5350.555. PMID:9438847.

Conrad, J.L., Bibian, A.J., Weinersmith, K.L., De Carion, D., Young, M.J., Crain, P., et al. 2016. Novel species interaction in a highly modified estuary: association of largemouth bass with Brazilian waterweed Egeria densa. Trans. Am. Fish. Soc. 145: 249-263. doi:10.1080/00028487.2015.1114521.

Dettinger, M. 2011. Climate change, atmospheric rivers, and floods in California-a multimodel analysis of storm frequency and magnitude changes. J. Am. Water Resour. Assoc. 47(3): 514-523. doi:10.1111/j.1752-1688.2011.00546.x.

Diffenbaugh, N.S., Swain, D.L., and Touma, D. 2015. Anthropogenic warming has increased drought risk in California. Proc. Natl. Acad. Sci. U.S.A. 112(13): 3931-3936. doi:10.1073/pnas.1422385112. PMID:25733875. 
Esri. 2011. ArcGIS Desktop: Release 10. Environmental Systems Research Institute, Redlands, Calif.

Gregory, R.S., and Levings, C.D. 1998. Turbidity reduces predation on migrating juvenile Pacific salmon. Trans. Am. Fish. Soc. 127: 275-285. doi:10.1577/15488659(1998) $127<0275:$ TRPOMJ $>2.0$.CO;2.

Grossman, G.D. 2016. Predation on fishes in the Sacramento-San Joaquin delta: Current knowledge and future directions. SFEWS. 14(2): Art. 8. doi:10.15447/sfews.2016v14iss2art8.

Harnish, R.A., Johnson, G.E., McMichael, G.A., Hughes, M.S., and Ebberts, B.D. 2012. Effect of migration pathway on travel time and survival of acoustictagged juvenile salmonids in the Columbia River estuary. Trans. Am. Fish. Soc. 141(2): 507-519. doi:10.1080/00028487.2012.670576

Hestir, E.L., Schoellhamer, D.H., Greenberg, J., Morgan-King, T., and Ustin, S.L. 2016. The effect of submerged aquatic vegetation expansion on a declining turbidity trend in the Sacramento-San Joaquin river delta. Estuaries Coasts, 39: 1100-1112. doi:10.1007/s12237-015-0055-z.

Hosmer, D.W., and Lemeshow, S. 2000. Applied logistic regression. 2nd ed. Wiley, New York.

Lady, J.M., and Skalski, J.R. 2009. USER 4: user-specified estimation routine. Columbia Basin Research, School of Aquatic and Fishery Sciences, University of Washington, Seattle. Available from http://www.cbr.washington.edu/ analysis/apps/user.

Li, T., and Anderson, J.J. 2009. The vitality model: a way to understand population survival and demographic heterogeneity. Theor. Popul. Biol. 76(2): 118-131. doi:10.1016/j.tpb.2009.05.004. PMID:19500610.

Liedtke, T.L., Beeman, J.W., and Gee, L.P., 2012. A standard operating procedure for the surgical implantation of transmitters in juvenile salmonids. US Geological Survey, Open-File Report 2012-1267, Reston, Virginia. Available from https://pubs.usgs.gov/of/2012/1267/pdf/ofr20121267.pdf.

Lindley, S.T., Schick, R.S., Agrawal, A., Goslin, M., Pearson, T.E., Mora, E., et al. 2006. Historical population structure of Central Valley steelhead and its alteration by dams. SFEWS. 4(1): Art. 3. doi:10.15447/sfews.2006v4iss1art3.

Magnusson, A., and Hilborn, R. 2003. Estuarine influence on survival rates of coho (Oncorhynchus kisutch) and Chinook salmon (Oncorhynchus tshawytscha) released from hatcheries on the US Pacific coast. Estuaries, 26: 1094-1103. doi:10.1007/BF02803366.

Martinelli, T.L., Hansel, H.C., and Shively, R.S. 1998. Growth and physiological responses to surgical and gastric radio transmitter implantation techniques in subyearling chinook salmon (Oncorhynchus tshawytscha). Hydrobiologia, 371: 79-87. doi:10.1023/A:1017019006039.

McCullagh, P., and Nelder, J. 1989. Generalized linear models, 2nd ed. Chapman and Hall, London.

McEwan, D.R. 2001. Central Valley Steelhead. In Contributions to the biology of Central Valley salmonids. Vol. 1. Edited by R.L. Brown. Fish Bulletin 179. pp. 1-44. Available from https://escholarship.org/uc/item/6sd4z5b2 [accessed 1 June 2020].

Michel, C.J., Ammann, A.J., Lindley, S.T., Sandstrom, P.T., Chapman, E.D., Thomas, M.J., et al. 2015. Chinook salmon outmigration survival in wet and dry years in California's Sacramento River. Can. J. Fish. Aquat. Sci. 72(11): 1749-1759. doi:10.1139/cjfas-2014-0528.

Monsen, N.E., Cloern, J.E., and Burau, J.R. 2007. Effects of flow diversions on water quality and habitat quality: examples from California's highly manipulated Sacramento-San Joaquin Delta. SFEWS, 5(3). Art. 2. doi:10.15447| sfews. 2007v5iss5art2.

Moyle, P.B., Israel, J.A., and Purdy, S.E. 2008. Salmon, steelhead, and trout in California: status of an emblematic fauna. Report for California Trout, 2008. Available from https://watershed.ucdavis.edu/library [accessed 1 June 2020].

Moyle, P.B., Bennett, W.A., Fleenor, W.E., and Lund, J.R. 2010. Habitat variability and complexity in the upper San Francisco Estuary. SFEWS. 8(3). doi:10.15447/sfews.2010v8iss3art1.

Moyle, P.B., Lusardi, R.A., Samuel, P.J., and Katz, J.V.E. 2017. State of the salmonids: status of California's emblematic fishes 2017. Center for Watershed Sciences, University of California, Davis and California Trout, San Francisco, California. Available from https://caltrout.org/wp-content/uploads/ 2017/08/SOS-II_Final.pdf [accessed 9 December 2020].

Murphy, D.D., Weiland, P.S., and Cummins, K.W. 2011. A critical assessment of the use of surrogate species in conservation planning in the SacramentoSan Joaquin Delta, California. Conserv. Biol. 25: 873-878. doi:10.1111/j.15231739.2011.01711.x. PMID:21790783.

Nam, B.-H., and D'Agostino, R.B. 2002. Discrimination index, the area under the ROC curve. In Goodness-of-fit tests and model validity. Edited by C. Huber-Carol, N. Balakrishnan, M.S. Nikulin, and M. Mesbah. Birkhauser Verlag, Boston.

National Marine Fisheries Service. 2009. Endangered Species Act Section 7 Consultation: Biological opinion and conference opinion on the longterm operations of the Central Valley Project and State Water Project. National Marine Fisheries Service, Southwest Region, Long Beach, California. Available from https://www.fisheries.noaa.gov/resource/document/ biological-opinion-and-conference-opinion-long-term-operations-central-valley [accessed 15 October 2020].

National Oceanic and Atmospheric Administration Fisheries Salmon Scoping Team. 2017. Effects of water project operations on juvenile salmonid migration and survival in the south delta. Appendix B: Effects of water project operations on delta hydrodynamics. Technical report prepared for Collaborative Adaptive Management Team. Available from https:// www.fisheries.noaa.gov/resource/document/effects-water-project-operationsjuvenile-salmonid-migration-and-survival-south.

Nelson, T.R., Michel, C.J., Gary, M.P., Lehman, B.M., Demetras, N.J., Hammen, J.J., and Horn, M.J. 2020. Effects of artificial lighting at night on predator density and salmonid predation. Trans. Am. Fish. Soc. 150: 147-159. doi:10.1002/tafs.10286.

Nobriga, M.L., and Feyrer, F. 2007. Shallow-water piscivore-prey dynamics in California's Sacramento-San Joaquin delta. SFEWS. 5(2): Article 4. doi:10.15447| sfews.2007v5iss2art4.

Perry, R.W., Skalski, J.R., Brandes, P.L., Sandstrom, P.T., Klimley, A.P., Ammann, A., and MacFarlane, B. 2010. Estimating survival and migration route probabilities of juvenile Chinook salmon in the Sacramento-San Joaquin River Delta. N. Am. J. Fish. Manage. 30(1): 142-156. doi:10.1577/M08-200.1.

Perry, R.W., Brandes, P.L., Burau, J.R., Klimley, A.P., MacFarlane, B., Michel, C., and Skalski, J.R. 2013. Sensitivity of survival to migration routes used by juvenile Chinook Salmon to negotiate the Sacramento-San Joaquin River Delta. Environ. Biol. Fish. 96: 381-392. doi:10.1007/s10641-012-9984-6.

Perry, R.W., Pope, A.C., Romine, J.G., Brandes, P.L., Burau, J.R., Blake, A.R., et al. 2018. Flow-mediated effects on travel time, routing, and survival of juvenile Chinook salmon in a spatially complex, tidally forced river delta. Can. J. Fish. Aquat. Sci. 75(11): 1886-1901. doi:10.1139/cjfas-2017-0310.

$\mathrm{R}$ Core Team. 2020. R: a language and environment for statistical computing. R Foundation for Statistical Computing, Vienna, Austria. Available from https://www.R-project.org/.

Rechisky, E.L., Welch, D.W., Porter, A.D., Jacobs-Scott, M.C., and Winchell, P.M. 2013. Influence of multiple dam passage on survival of juvenile Chinook Salmon in the Columbia River estuary and coastal ocean. Proc. Natl. Acad. Sci. U.S.A. 110(17): 6883-6888. doi:10.1073/pnas.1219910110. PMID:23576733.

Sandstrom, P.T., Ammann, A.J., Michel, C., Singer, G., Chapman, E.D., MacFarlane, R.B., et al. 2020. Low river survival of juvenile steelhead in the Sacramento River watershed. Environ. Biol. Fish. 103: 531-541. doi:10.1007/s10641-020-00954-z.

Satterthwaite, W.H., Beakes, M.P., Collins, E.M., Swank, D.R., Merz, J.E., Titus, R.G., et al. 2010. State-dependent life history models in a changing (and regulated) environment: steelhead in the California Central Valley. Evol. Appl. 3(3): 221-243. doi:10.1111/j.1752-4571.2009.00103.x. PMID:25567921.

Singer, G.P., Hearn, A.R., Chapman, E.D., Peterson, M.L., LaCivita, P.E., Brostoff, W.N., et al. 2013. Interannual variation of reach specific migratory success for Sacramento River hatchery yearling late-fall-run Chinook salmon (Oncorhynchus tshawytscha) and steelhead trout (Oncorhynchus mykiss). Environ. Biol. Fishes, 96: 363-379. doi:10.1007/s10641-012-0037-y.

Sinokrot, B.A., and Gulliver, J.S. 2000. In-stream flow impact on river water temperatures. J. Hydraul. Res. 38(5): 339-349. doi:10.1080/00221680009498315.

Sokal, R.R., and Rohlf, F.J. 1995. Biometry. 3rd ed. Freeman, New York.

Sommer, T., Armor, C., Baxter, R., Breuer, R., Brown, L., Chotkowski, M., et al. 2007. The collapse of pelagic fishes in the upper San Francisco Estuary. Fisheries, 32(6): 270-277. doi:10.1577/1548-8446(2007)32[270:TCOPFI]2.0.CO;2.

Swain, D.L., Langenbrunner, B., Neelin, J.D., and Hall, A. 2018. Increasing precipitation volatility in twenty-first century California. Nat. Clim. Change, 8: 427-433. doi:10.1038/s41558-018-0140-y.

Thorstad, E.B., Whoriskey, F., Uglem, I., Moore, A., Rikardsen, A.H., and Finstad, B. 2012. A critical life stage of the Atlantic salmon Salmo salar: behaviour and survival during the smolt and initial post-smolt migration. J. Fish Biol. 81(2): 500-542. doi:10.1111/j.1095-8649.2012.03370.x. PMID:22803722.

Townsend, R.L., Skalski, J.R., Dillingham, P., and Steig, T.W. 2006. Correcting bias in survival estimation resulting from tag failure in acoustic and radiotelemetry studies. J. Agric. Biol. Environ. Stat. 11: 183-196. doi:10.1198/ $108571106 \mathrm{X} 111323$.

USBR. 2018a. NMFS Biological Opinion RPA IV.2.2: 2011 six-year acoustic telemetry steelhead study. Contributions by Buchanan, R.A., Israel, J.A., Brandes. P., and Buttermore, E. US Bureau of Reclamation Bay-Delta Office, Mid-Pacific Region, Sacramento, California, United States. Final Report 14 May 2018.

USBR. 2018b. NMFS Biological Opinion RPA IV.2.2 2012. six-year acoustic telemetry steelhead study. Contributions by Buchanan, R.A., Brandes, P., Israel, J.A., and Buttermore, E. US Bureau of Reclamation Bay-Delta Office, Mid-Pacific Region, Sacramento, California, United States. Final Report 16 May 2018.

USBR. 2018c. NMFS Biological Opinion RPA IV.2.2: 2013 Six-Year Acoustic Telemetry Steelhead Study. Contributions by Buchanan, R.A., Brandes, P., Israel, J.A., and Buttermore, E. US Bureau of Reclamation Bay-Delta Office, Mid-Pacific Region, Sacramento, California, United States Final Report. June 2018.

Welch, D.W., Melnychuk, M.C., Payne, J.C., Rechisky, E.L., Porter, A.D., Jackson, G.D., et al. 2011. In situ measurement of coastal ocean movements and survival of juvenile Pacific salmon. Proc. Natl. Acad. Sci. U.S.A. 108(21): 8708-8713. doi:10.1073/pnas.1014044108. PMID:21558442.

Yoshiyama, R.M., Fisher, F.W., and Moyle, P.B. 1998. Historical abundance and decline of Chinook salmon in the Central Valley region of California. N. Am. J. Fish. Manage. 18(3): 487-521. doi:10.1577/1548-8675(1998)018<0487: HAADOC > 2.0.CO;2. 